\title{
Dynamic roles of microRNAs in nutrient acquisition and plant adaptation under nutrient stress: A review
}

\author{
Raheel Shahzad ${ }^{1 * \dagger}$, Putri Widyanti Harlina ${ }^{2} \dagger$, Mohammed Ayaad ${ }^{1,3}$, Mohamed Ewas ${ }^{1,4}$, Elsayed Nishawy ${ }^{1,4}$, \\ Shah Fahad ${ }^{5}$, Hizar Subthain ${ }^{1}$, Mohamed H. Amar ${ }^{4}$
}

${ }^{1}$ National Key Laboratory of Crop Genetic Improvement and National Center of Plant Gene Research, Huazhong Agricultural University, Wuhan 430070, China

${ }^{2}$ Department of Food Science and Technology, Huazhong Agricultural University, Wuhan 430070, China

${ }^{3}$ Department of Plant Research, Radioisotopes Application Division, Nuclear Research Center of Atomic Energy Authority, Inshas, Egypt

${ }^{4}$ Egyptian Deserts Gene Bank (EDGB), Genetic Resources Department, Desert Research Center (DRC), Cairo, Egypt

${ }^{5}$ Department of Plant Science and Technology, Huazhong Agricultural University, Wuhan 430070, China

tRaheel Shahzad and Putri Widyanti Harlina contributed equally to this work.

*Corresponding author: raheel.shahzad@webmail.hzau.edu.cn

\begin{abstract}
A constant supply of soil nutrients is critical for the normal growth and development of plants. However, most environments are unstable and this variability depends on numerous factors that include availability of water content, $\mathrm{pH}$, redox potential, an abundance of organic matter as well as microorganisms in soils. To overcome these hurdles and to maintain nutritional homeostasis, plants have evolved sophisticated systems for the continuous provision of soil nutrients necessary for their uninterrupted growth. In this pressing scenario, plant microRNAs (miRNAs) have emerged as a central regulator of nutrients uptake and transport during limited nutrient conditions. Numerous studies establish the intrinsic involvement of miRNAs and their immediate targets facilitating the core mechanisms related to nutrient homeostasis. In this review, we focus on global overview of miRNAs and their dynamic roles involved in keeping nutritional balance within the plants mediated via post-transcriptional regulation by transcript cleavage or translational inhibition of their target mRNAs. In addition, we have also focused on some of the forefront plant adaptations mediated by miRNAs during nutrient deficiency, such as root architecture modifications, transport channel modulation, long distance signaling and subsequent nutrient mobilization through phloem. Moreover, plant strategy to bring out such alterations is a highly perplexing mechanism that requires changes at large scale which involves coordinated regulation of miRNAs and plant hormones at multiple levels. Deciphering the underlying miRNAs-based mechanisms for streamlining nutrient uptake and transport would be a giant step towards solving this conundrum.
\end{abstract}

Keywords: microRNAs, Nutrient acquisition, Mechanisms, Plant adaptation.

Introduction

Normal plant growth, development and yield extensively depend on constant supply of nutrients through the soil in any crop production system. There is a dynamic relationship of the plant's nutritional status with plant susceptibility to various pathogens as well as abiotic environmental stresses in both intensive and integrated cropping systems. Plant nutrients play key functions critical for maintaining growth and development including structural components, cellular exchanges, osmotic regulations as well as biosynthesis of essential metabolites (Takehisa et al., 2013). MiRNAs are diverse regulatory molecules of small size and are considered chief controllers for the growth and development of various plants. Several miRNAs have been found to take part in diverse functions and fundamentally involved in numerous physiological events, such as stem cell proliferation, leaf and floral development, flowering initiation, tissue and organ buildup, as well as regulation of positive responses to various biotic and abiotic stresses (Willmann and Poethig, 2005; Sunkar et al., 2007; Zhou et al., 2012; Guo et al., 2013; Song et al., 2013; Wang B et al., 2014; Li and Zhang, 2016; Gao et al., 2016; Jian et al., 2016). Since miRNAs are involved in the regulation of essentially all cellular metabolic pathways, transformation of their biogenesis is of supreme importance for the maintenance of cellular homeostasis. MicroRNAs (miRNAs) are small noncoding RNAs 20-24 nucleotides long that control gene expression by promoting degradation or repressing translation of target mRNAs. Biogenesis of miRNA starts with MIRNA genes transcription directed by DNA dependent RNA polymerase II to form pri-miRNAs (Kim, 2005). Additionally, MIR promoters contain the TATA-box and cis-regulatory motifs, which explains the transcriptional regulation of MIR expression (Zhao and Li, 2013). Lack of mediator (a multi-subunit complex) disrupts the recruitment of of Pol II 
to MIR promoters, thus affects the MIR transcription (Kim et al., 2011). Furthermore, spatio-temporal expression pattern for specific MIRs has also been noticed (Carlsbecker et al., 2010). The products of MIRNA genes transcription (pri-miRNAs) undergo series of post-transcriptional modifications through enzymatic actions, including formation of stem loop structure. Further processing of pri-miRNAs eventuates to form miRNA precursors often termed as pre-miRNAs. The self-complementary stem loop structure of pre-miRNAs, ultimately generate miRNA/miRNA* duplex mediated by dicer-like 1 (DCL1), a key enzyme in the miRNA biogenesis pathway. This conversion is also assisted by HYL1 (the dsRNA-binding protein hyponastic leaves1) and SE (zinc finger protein serrate), followed by methylation at the $3^{\prime}$ terminus by HEN1 (HUA1 enhancer1), which then subsequently exported out from the nucleus into the cytoplasm by hasty (HST1, a homolog of exportin 5). Inside the cytoplasm, miRNA strands of this duplex are recognized by ARGONAUTE (AGO) proteins; a central component of the RNA-induced silencing complex (RISC), which later becomes part of this complex (Chen, 2005). Several mechanisms explain the regulatory functions of miRNAs in plants. Most commonly, plant miRNAs direct AGO proteins to cleave target mRNA by near perfect base-pairing guided by endonuclease enzymes. Afterwards, rapid degradation of target mRNA carried out by the exosome and an exoribonuclease complex called XRN4. Additionally, some miRNAs limit the production of target protein by inhibiting its mRNA during translational phase ( Lanet et al., 2009). Similarly, miRNA can suppress the target gene expression at transcriptional stage through DNA methylation (Wu et al., 2010). It is not surprising that post-translational regulatory mechanism in plants is required for majority of proteins during cellular processes and that plant miRNA pathway is also subjected to this type of regulation. The phosphatases CPL1 and CPL2 function as HYL1 dephosphorylation. Also evidence suggests that HYL1, DCL1, SE, CPL1, CPL2, and RCF3 are part of the same protein complex at least in some cell types. However, role of CPL1 and RCF3 in the phosphorylation of SE and DCL1 is persuasive but still elusive. Further, the evidence of MPK3-mediated HYL1 phosphorylation is still not clear for in vivo activity. Similarly, interaction between AGO1 and its cofactors, necessary for specific silencing pathway needs further investigation (Figure 1).

Most recently, numerous miRNAs were reported for their exclusive involvement in nutrient elements uptake and transport in plants (Fischer et al., 2013; Kehr, 2013). Predominantly, miRNAs directly or indirectly target the transporter proteins to facilitate specific nutrient uptake and transport. However, numerous other targets were also identified in large number, details of which are provided in our next section. In this review, we focused on the current status of various nutrient-responsive miRNAs extensively reported in various studies, as summarized in Table 1. Moreover, their functional roles were strongly associated with nutrients uptake and mobilization in plants via complex regulatory mechanisms during nutrient deprivation. Understanding the mechanisms of miRNAs in response to nutrient scarce conditions would possibly shatter the barrier causing abnormal growth, development and yield loss in various crop plants. Deciphering the regulation of transporter genes by miRNAs might pave the way for biofortification or facilitate the bioavailability of essential nutrients in major crop plants. In this context, we focus not only on diverse roles of miRNAs to procure various nutrient elements but also discuss the miRNA-mediated plant adaptations under nutrient stress. Importantly, we have discussed in details, the regulatory capacity of set of miRNAs (conserved across many species) that play important roles in various nutrients uptake and mobilization. However, some novel miRNAs specific to one species or responsive to unique nutrient elements were also reported, thus showing the functional diversity among different species. In our next section, we have reviewed the diverse functional roles of miRNAs for systematic procurement of various nutrients, including Nitrogen $(N)$, Phosphorous $(P)$, Potassium $(K)$, Sulfur (S) and other mineral elements, especially Copper ( $\mathrm{Cu})$, Zinc (Zn), Iron (Fe), Manganese (Mn) and Boron (B).

\section{Nutrients uptake and transport in plants regulated by miRNAs}

\section{Nitrogen and diverse roles of miRNAs}

Plant growth and development primarily depends on presence of nitrogen $(\mathrm{N})$ in relatively large amounts in the plant cells, and considered as building block of amino acids, nucleic acids as well as chlorophyll. Moreover, tightly coordinated carbon and amino acid metabolism as well as protein synthesis, critical for routine cellular activities are fundamentally controlled by $\mathrm{N}$ availability (Crawford and Forde, 2002; Zheng, 2009). In this context, being a crucial element for plant growth, ample supply of $\mathrm{N}$ in the form of chemical $\mathrm{N}$ fertilizers is enforced for optimum crop yield each year. However, due to excess amounts of $\mathrm{N}$ utilization, phenomena of eutrophication linked with increased pollution in rivers and oceans, which is extremely alarming for maintaining a healthy ecosystem (Canfield et al., 2010). Therefore, decreasing the overreliance on the use of $\mathrm{N}$ fertilizers and to increase $\mathrm{N}$ utilization efficiency (NUE), necessitated a substantial discernment underlying its regulatory components including $\mathrm{N}$ uptake, translocation as well as remobilization. The major sources of $\mathrm{N}$ in the soil available to the plants, i.e. ammonia/ammonium ion $\left(\mathrm{NH}_{3} / \mathrm{NH}_{4}{ }^{+}\right)$, nitrate $\left(\mathrm{NO}_{3}{ }^{-}\right)$, organic $\mathrm{N}$ (e.g. free amino acids) acquired through microbial symbiosis by using nitrogenase enzyme complex (Fischer et al., 2013).

Uptake of $\mathrm{NO}_{3}{ }^{-}$from the soil, however, is a complex mechanism where several root-specific transporters unified to carry out their functions. In plant kingdom, four major $\mathrm{NO}_{3}{ }^{-}$transporter families have been identified including nitrate transporter 1 /peptide transporter family (NRT1/PTR or NPF), nitrate transporter 2 family (NRT2), chloride channel family $(C L C)$, and slow anion channel-associated homologues (SLAC/SLAH), which are collectively involved in $\mathrm{NO}_{3}{ }^{-}$uptake, allocation as well as sensing (Boursiac et al., 2013). Plants have evolved two types of nitrate transport systems: high-affinity transport system (HATs) and low-affinity transport system (LATs), which are required to effectively scavenge ions from the soil depending on its concentration (Glass and Siddiqi, 1995). However, the members of HATs and LATs can both be constitutive; without $\mathrm{NO}_{3}{ }^{-}$supply, and $\mathrm{NO}_{3}{ }^{-}$inducible; stimulated by $\mathrm{NO}_{3}{ }^{-}$present in external medium (Miller et al., 2007). 
Table 1. Differentially expressed miRNA families responsive under various nutrients stress.

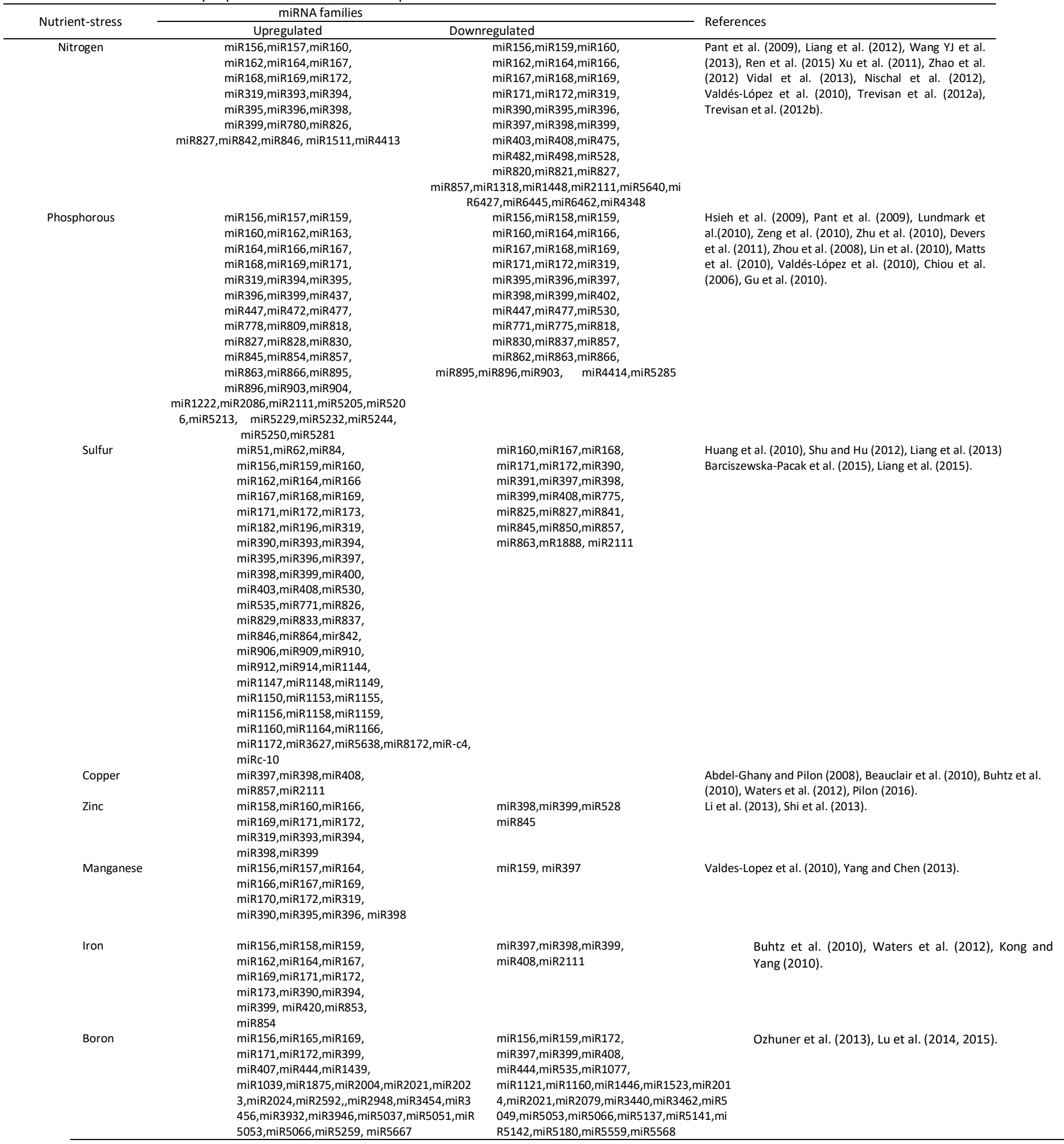




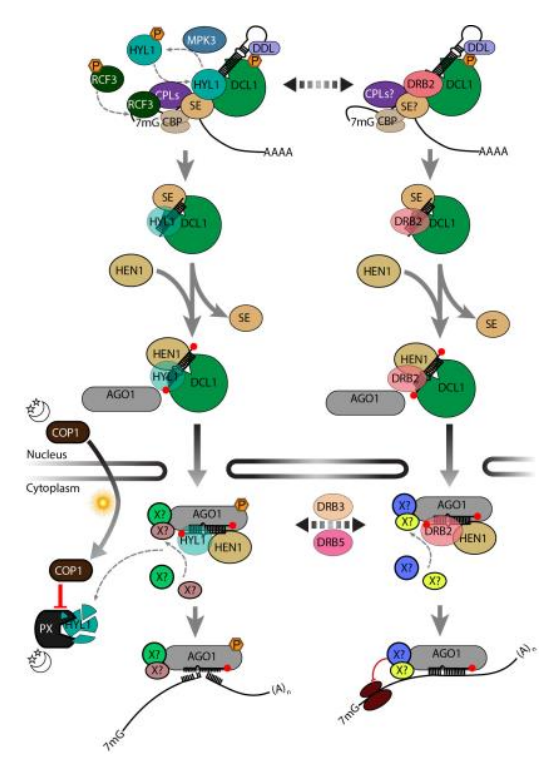

Fig 1. A model adapted from Achkar et al. 2016 (*see details below), representing miRNA biogenesis machinery and its post-translational regulation. Phosphorylation of miRNA biogenesis cofactors are essential for precise functioning of the pathway in plants. The phosphatases CPL1 and CPL2 dephosphorylate HYL1 and RCF3, followed by accurate DCL1 processing which is involved in miRNA biogenesis and splicing, ultimately leads to correct strand selection by AGO1. The putative phosphorylation of $D C L 1$ helicase domain allows its interaction with $D D L$ and the stabilization of the pri-miRNA. The complex processing depicted in this figure, showing the post-translational modification triggered by HYL1/DRB2 or switching between AGO1 and its cofactors (X), thus, corroborate specific silencing pathway. A dynamic flux of the pathway can also be seen through HEN1-mediated miRNA methylation, which proceeds through HEN1 interaction with DCL1 and HYL1. HEN1 also interacts with SE, which connote the tight interconnection between different components of miRNA machinery necessary for pri-miRNA progression to mature miRNA. However, substantial efforts are still required to fully understand the dynamics of recruitment, assembly, action, and disassembly of the components of the miRNA machinery. ${ }^{*}$ This figure is adapted from Achkar et al. (2016) and reprinted with permission from Elsevier.

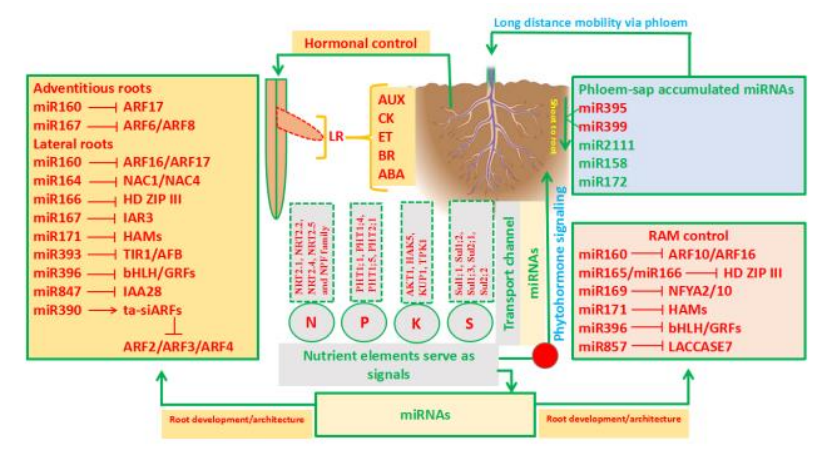

Fig 2. A model illustrating miRNAs-based plant strategies comprising long distance mobility, root architecture modifications, transportchannel modulation alongwith hormonal control during nutrient stress regulation. Distinct nutrient elements that serve as signals molecules and activate several miRNAs, which in turn target numerous gene expressions predominantly members of plant transcription factors, such as ARFs, GRFs, NACs and others. miRNAs and their targeted-member of plant TFs participate specifically in root development and architecture, such as controlling root apical meristem (RAM; indicated in pink box), adventitious and lateral root (LR) formation (yellow box). However, LR formation that includes LR initiation, LR development and LR emergence is a complex mechanism that regulates through numerous hormones i.e. AUX, CK, ET, BR and ABA. Nutrient signaling interacts with phytohormones signaling ( $\mathrm{indicating}$ the interaction between them), thus alters the expression of set of miRNAs, consequently, nutrient-specific transporters (indicated in green dotted box) are coordinately regulated with plant hormones and miRNAs to modulate overall transport channel required for precise nutritional balance within the plants. Importantly, phloem accumulated miRNAs (light blue box) are necessary for nutrient mobility too far off places i.e. shoot to root translocation (such as miR395 and miR399 are major players during this mobilization). 


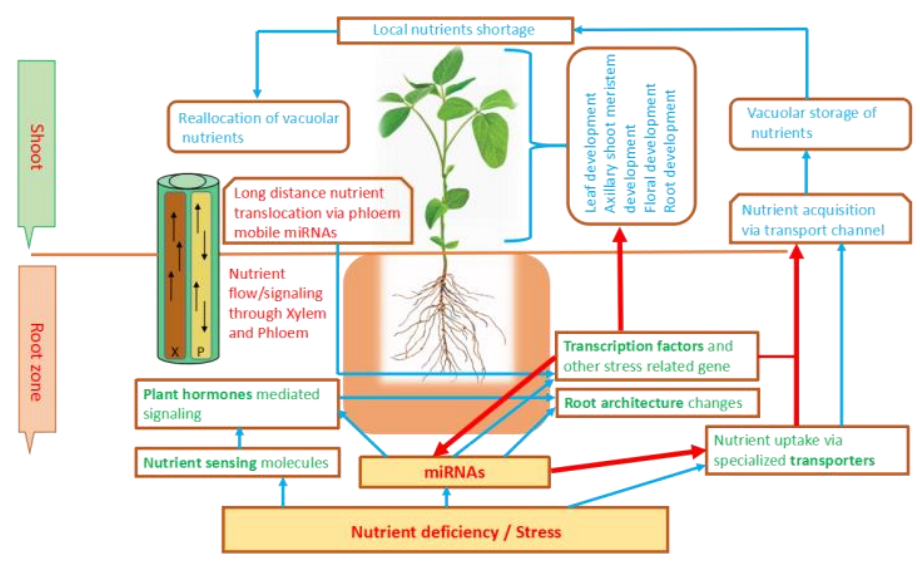

Fig 3. General scheme representing the involvement of miRNAs during nutrient stress response and relationship among transcription factors, plant development and miRNAs. Shortages of various nutrients are sensed by nutrient sensing molecules, which in turn trigger plant hormones signaling specifically required by plants for root architecture modifications. Nutrient stress upregulate countless miRNAs and uptake of distinct nutrients take place via specialized transporters, thus modulating overall transport channel for efficient nutrient acquisition. However, this phenomena is mediated by number of plant transcription factors (TFs), some of which are direct targets of miRNAs, conversely, most TFs modulate the miRNA expressions by binding to its promoter sites e.g. MYB2 binds directly to MYB-binding site in the miR399 promoter. Additionally, wide array of transcription factors play fundamental roles in numerous plant development processes including leaf development, floral development, axillary shoot meristem control as well as root development (In this model TFs regulation of miRNAs, transport channel and plant development are indicated by red arrows). Importantly, phloem mobile miRNAs participate in long distance signaling that takes place through phloem $(\mathrm{P})$ and xylem $(\mathrm{X})$, thus maintaining nutrient homeostasis across whole plant level.

\section{MiRNAs and their targets under low nitrogen}

Several attempts have been made in order to comprehend molecular functioning of plant components involved in $\mathrm{N}$ sensing and to pinpoint $\mathrm{N}$-responsive genes. However, a plant adjustment to $\mathrm{N}$ availability is a complex process that includes tortuous physiological and biochemical modifications controlled by plethora of genes and metabolic pathways. Numerous studies have been conducted to establish the robust contributions of miRNAs responsive to $\mathrm{N}$ stimulus in different plant species, thus, several differentially expressed $\mathrm{N}$-responsive miRNAs were identified (Table 1).

Rice is one of the most important cereal crops worldwide, while in Asia alone, it fulfils nearly $50 \%$ of caloric needs of approximately 520 million people (Muthayya et al., 2014). In order to get a global overview on miRNAs involved in $\mathrm{N}$ response in rice, a study conducted by Li et al. (2016) based on high-throughput small RNA sequencing revealed a total of 44 miRNAs differentially expressed in response to high- $N$ and low- $\mathrm{N}$ conditions. Further, this study also characterized dissimilar responses of miRNAs to different $\mathrm{N}$ sources i.e. under different ammonium and nitrate treatments. By analyzing the target genes of miRNAs under this investigation, most of them were belonging to plant transcription factor families and proteins related with various metabolic pathways or stress responses. A study conducted in maize, using different levels of $\mathrm{N}$ deficiency i.e under chronic and transient nitrate limiting conditions, and the identified miRNAs were showing overlapping or unique expressions under the given $\mathrm{N}$ limiting conditions in tissue dependent manner (Xu et al., 2011). Similarly, another study in maize revealed the involvement of six mature nitrate-responsive miRNAs. Moreover, in situ hybridization method employed in this study, demonstrated the influence of nitrate availability on both the amount as well as localization of the miRNAs. The results showed that transcripts for all the miRNAs were accumulated in the roots of the plant supplied with $\mathrm{N}$, while the roots limited in $\mathrm{N}$-supply display reduced expressions (Trevisan et al., 2012a) To deepen the molecular understanding for the involvement of these six miRNAs under nitrate starvation, spatio-temporal expression pattern was confirmed through in situ detection and real time PCR analysis. Further, results also suggested that extended $\mathrm{N}$-limited conditions may activate a post-transcriptional control by inducing the expression of target genes, which might actively suppress miRNAs under this investigation (Trevisan et al., 2012b). Due to the fact that almost all major cereal crops including wheat, maize and rice depend heavily on nitrogen application to maintain their optimum production, ideally, there is great need of genotypes that allow maximum uptake of $\mathrm{N}$ in order to improve nitrogen use efficiency (Garnett et al., 2015). A study performed by Zhao et al. (2015) in wheat, investigated 38 wheat miRNAs (TaMIRs) under optimal $\mathrm{N}$ and $\mathrm{N}$-depleted conditions. The results revealed that most of the TaMIRs were responsive to limited $\mathrm{N}$ concentrations and showed distinct pattern of expression, while TaMIR399 and TaMIR1133, being downregulated. Further, this report also suggested that $\mathrm{N}$-concentration and limited- $\mathrm{N}$ duration are inversely related with the expression of specific TaMIRs under investigation. A recent study performed under normal and limited nitrate conditions in two wheat genotypes (Sinha et al., 2015), detected a set of ten differentially expressed miRNAs in plant roots. Some notable differences among their expressions were depending on both the genotype and the level of $\mathrm{N}$ availability. However, other reported wheat miRNAs were not detectable in the samples 
under investigation, both under normal and starved $\mathrm{N}$ conditions.

Beside major crops, there are several studies demonstrating $\mathrm{N}$-responsive miRNAs expressed in a distinct pattern, a study carried out in soybean (Wang et al., 2013), where authors have generated sixteen libraries from two genotypes i.e. low $\mathrm{N}$ sensitive and low $\mathrm{N}$ tolerant, and found significant differentially expressed miRNAs both in shoots and roots under short-term or long-term $\mathrm{N}$ stress. Exploring miRNAs expression under low-N conditions, an earlier study conducted in common bean (Valdés-López et al., 2010), demonstrated a suppression of tested miRNAs expression in root and leave tissues under limited-N scenario, with the exception of miR396 being upregulated. Another study in French bean (Babu et al., 2014), revealed nine potential miRNAs analyzed by RT-PCR. They concluded that expression of miR172 family was induced upon low nitrate stress while miR169 family was repressed. Numerous studies in model plant, Arabidopsis, characterized the involvement of miRNAs in response to limited $\mathrm{N}$ conditions in plant seedlings (Pant et al., 2009; Liang et al., 2012). Likewise, an investigation carried out in the roots of Arabidopsis plant found a new $\mathrm{N}$-responsive miRNA (miR5640) and its target (AtPPC3) protein in a different study (Vidal et al., 2013). Other recent report in model plant, Populus tomentosa, used degradome sequencing technology to detect and validate $\mathrm{N}$ stress responsive miRNAs (Chen et al., 2015). A study using high throughput sequencing technology reported in ornamental plant (Chrysanthemum nankingense), native to China, revealed the differential expression of 81 miRNAs in roots and 101 miRNAs in leaves of the plant when exposed to low nitrogen level (Song et al., 2015). Taking together, these evidence strongly suggest a noticeable role of miRNAs in response to low nitrogen conditions, however, the distinct expression of miRNAs involved could be due to variations in experimental conditions ( $\mathrm{N}$ concentration), tissues under observation, and plant species. Although, a massive data obtained through deep sequencing technologies, which facilitated to identify potential miRNAs under $\mathrm{N}$ stress, however, there is a huge capacity to explore and validate miRNAs and their respective targets to deepen our understanding about miRNAs-mediated molecular adaptations in plants under limited $\mathrm{N}$ settings.

\section{Biological $\mathrm{N}$-fixation and miRNAs}

Plants in the legume family form symbioses with nitrogen-fixing soil bacteria or rhizobia that provide a sustainable nitrogen source to improve soil fertility in agricultural settings. Symbiotic nitrogen fixation is central to any plant for energy-sustainable production of food or fuel. Crop plants for food, oil, and green manure are able to produce high-protein seeds and leaves because of the fixed nitrogen provided by the bacteria. Beside the well-studied functions of miRNAs in $\mathrm{N}$ sensing and signaling, extensive reports are also being established to characterize their prominent roles in the phenomena of plant-microbe symbiosis. A notable number of studies in leguminous crops including Glycine max and Medicago truncatula, supported this fact and several miRNAs were identified to actively participate during this mutually beneficial interaction. In this context, an earlier study conducted by Subramanian et al. (2008) demonstrated that potential miRNAs were regulators in nodule development in soybean roots when inoculated with Bradyrhizobium japonicum and function in symbiotic $\mathrm{N}$ fixation. The study findings validated by northern analysis confirmed the dynamic regulation of involved miRNAs and results were consistent with miRNA abundance in sequence libraries. The selected miRNAs were independently investigated for expression pattern through northern analysis. Among them, miR168 and miR172 were firstly upregulated immediately one hour post inoculation, while a decreased pattern of expression was observed after this point. Further, after the inoculation by Bradyrhizobium japonicum, miR159 and miR393 were found to be induced in time dependent manner. On the other hand, miR160 and miR169 were suppressed during response to rhizobia, suggesting the dynamic role of specific miRNAs in modulating signaling and nutrient homeostasis during nodulation. Importantly, miR393 and miR160 were already characterized to be involved in plant-pathogen synergy and substantially enhanced basal plant immunity (Subramanian et al., 2008; Simon et al., 2009). Another study conducted by Wang et al. (2009), demonstrated the involvement of miRNAs during symbiotic $\mathrm{N}$ fixation in root nodules of soybean. The authors found that four miRNA families in soybean (miR1507, miR1508, miR1509, and miR1510), detected during legume-rhizobium symbiosis were similar as described by previous report (Subramanian et al., 2008). The results also confirmed the dynamic expression of miRNAs in different tissues of soybean plant including functional root nodules. The significant increase of expressions of miR172 and miR2107 were noticed in root nodules, however, miR396, miR1508, and miR1509 were suppressed in functional nodules during symbiotic $\mathrm{N}$ fixation. Moreover, the potential targets of these functional nodules related miRNAs, consistent with earlier studies, were predicted as families of various transcription factors (TFs), which are fundamentally involved in hormone mediated signaling, developmental related proteins, defense associated responses as well as nitrate transporters. Later studies also supported the earlier reports demonstrating the involvement of miRNAs at initial stages of root nodulation. In soybean, miR1530, miR1520, and miR1522 were detected in roots and were found to be involved at initial stages of nodules development (Barros-Carvalho et al., 2014). Consistent with previous report (Subramanian et al., 2008), these miRNAs contributed in the regulation of nodule functioning in the soybean thereby facilitating nodule organogenesis and symbiotic interactions. Also, plant TFs were targets of nodules specific miRNAs as characterized in previous study (Joshi et al., (2010).

Notably, few miRNAs are conserved across several species, however, mostly they were detected as species-specific such as miR1507 to miR1510 were found in Fabaceae family, while miR1520, miR1522, miR1530, miR2107, and miR4393 were classified in soybean. Similarly, there is a large number of $G$. max and $M$. truncatula specific miRNAs already reported in several studies (Cuperus et al., 2011). Concomitantly, myriad functions of miRNAs would emerge through in depth studies of various plant species. Comprehensive studies of rice and Arabidopsis already validated diverse functioning roles of miRNAs thereby simultaneously affecting distinct metabolic pathways. The root apex contains meristematic cells that control root development and triggers all other organs under the ground 
surface. A study conducted in $M$. truncatula by Lelandais-Briere et al. (2009) using in situ hybridization, demonstrated the identification of specialized miRNAs accumulated in meristematic tissues of root nodules, therefore, suggesting that miRNA mediated regulatory control might be involved in nodule development. Analysis of specific miRNAs in distinct tissues of mature nodules also supported this finding. In this context, it was understood that development of species specific miRNAs were later evolved and developed into factors involved in the symbiotic interactions suggesting the complex mechanism of unique miRNA activities at spatio-temporal level. Moreover, miRNAs were also explored exclusively in soybean roots which resulted in symbiotic interaction between nodules and nitrogen fixing bacteria. In this case, overexpression of miR160 in soybean culminated in reduced root nodules as reported by Turner et al. (2013). This report demonstrated that overexpression of miR160 resulted in auxinhypersensitive plants obtained through silencing of set of ARFs i.e ARF10/16/17; which consist of gene family that act as transcription activators or repressors by binding to specific promoters of early auxin responsive genes. Further, this study validated that roots of miR160-overexpressed plants had significantly reduced nodules as compared to vector control; however, auxin-hypersensitivity inhibited the formation of nodules primordium and development but did not influence root hairs in soybean. Conversely, another study revealed that enhanced expressions of specific miRNAs in soybean, such as miR482, miR1512, and miR1515 significantly contributed to increasing root nodulation to regulate the symbiotic process ( $\mathrm{Li}$ et al., 2010). Another study determined the contrasting roles of miR156 and miR172 in regulating the nodule development which concomitantly affecting nitrogenase activity. Ectopic expression of miR172 increased the expression of both symbiotic leghemoglobin and hemoglobin in transgenic roots of soybean plants, which resulted in enhanced nodulation. However, miR172 suppressed its target TF (AP2) and positively regulate nodulation while miR156 targets the expression of TF $(S P L)$ and negatively regulated the expression of miR172 thereby controlling hemoglobin expression which ultimately resulted in significantly reduced nodulation (Yan et al., 2013). In recent past, another study in soybean revealed the involvement of miR172 in symbiotic interaction by modulating signaling cascade regulating the process of nodules development (Wang Y et al., 2014). The induction of miR172c was observed during inoculation with compatible B. japonicum or lipooligosaccharide Nod factor accompanied by elevated expression specifically during nodulation. Overexpression of miR172c positively regulated both nodule initiation and number thereby suppressing its target gene, Nodule Number Control1, which directly controls the transcriptional activation of nodulin gene (ENOD40) by binding to its promoter. Importantly, expression levels of miR172c were regulated by both Nod Factor Receptor $1 \alpha / 5 \alpha$-mediated activation and by auto regulation of nodulation-mediated inhibition. Few other conserved miRNAs such as miR166 and miR396 were also corroborated to be involved in symbiosis and nodules development process in $M$. truncatula. Overexpression of miR166 in M. truncatula resulted in decreased lateral roots and nodule development thereby causing alterations in vascular tissues. Moreover, miR166-mediated regulation involved cleavage of several class III HD-ZIP TFs and markedly affecting their stability, which showed notable defects in the lateral root formation and reduced the number of functional nodules (Boualem et al., 2008; Simon et al., 2009). Likewise, a study performed by Bazin et al. (2013) observed dynamic expression of miR396 in distinct tissues of roots, with discriminative expression in the transition zone and exhibited differential expression pattern during lateral root and nodule organogenesis. Overexpression of miR396 targets six growth-regulating factors (GRFs) and two bHLH-79-like genes in transgenic roots, which downregulate their expressions and concomitantly altered symbiotic interaction and roots architecture in M. truncatula. Another legume species, Lotus japonicus, was also studied in this context and two miRNAs, miR171 and miR397 were identified to participate in symbiotic interaction and nodule functioning (De Luis et al., 2012). This report demonstrated that miR171 which targets the nodulation-associated TF, Nodulation Signaling Pathway 2 (NSP2), and regulated specifically during symbiotic bacterial infection. Moreover, qRT-PCR analysis revealed differential expressions of miR171 and its target TF (NSP2) in various plant tissues, where relative expression level of miR171 was increased 30 -fold in nodules as compared to roots; conversely, the expression of NSP2 was lower in nodules. Importantly, these results were intriguing in the context that conserved miR171 target SCL and its homologue genes in plant species, indicating the eminence to identify miRNA isoforms regulating alternative targets, consequently, modulating diverse functioning in plants. In case of miR397, whose expression elevated in mature nodules but highly dependent on their $\mathrm{N}$ fixing ability and compatible symbiotic interaction. On the other hand, the expression of miR397 was much lower in non-compatible microsymbiont or inactive nodules, implying that both factors are required for its regulation. Further, miR397 targets copper containing LACCASE-like genes, and its regulation involved copper homeostasis, denoting a significant link between two different pathways interacting for nutritional balance in legumes.

\section{Phosphorous and diverse roles of miRNAs}

Phosphorous $(P)$, being macronutrient, crucial for many fundamental plant processes including key metabolic pathways, and is essentially part of cell molecules such as nucleic acid, phospholipids, ATP, and sugars (Byrne et al., 2011). Although the availability of $P$ in the soil is abundant, however, other factors such as interaction with soil constituents, precipitation or its biological conversion to organic form affects its uptake and accessibility from the soil to the plants (Kirkby and Johnston, 2008). Under $P$ deficiency, plants modulate its adaptive mechanisms thereby adjusting its transcriptional and biochemical regulation in different tissues/organs to facilitate $P$ uptake and transport. An organized system for $P$ transport is required to intake $P$ from the soil by means of roots, and efficiently distributes it across various tissues of the whole plant. Given that, plants have evolved very sophisticated transport mechanisms for $\mathrm{P}$ uptake and circulation to different plant parts, as well as efflux system in P-limited soils for mobilization and redistribution (Chiou and Lin, 2011). P assimilation from the soil into the plant, and its 
distribution across other plants parts depends chiefly on two types of transporters: PHOSPHATE TRANSPOTERS (PHTs); which belongs to the family of phosphate: $\mathrm{H}^{+}$symporters (PHS) within the major facilitator superfamily (MFS), and other is PHOSPHATE 1 (PHO1) transporter; which belongs to SPX-EXS protein family (Mlodzinska and Zboinska, 2016).

\section{MiRNAs and their targets under limited phosphorous}

Numerous approaches were used to identify P-responsive miRNAs, high throughput sRNA sequencing being the most commonly used method, which facilitated a huge data collection in different plants. Based on numerous data collection methods and in different plant species, up- and down- regulation of P-specific miRNAs are summarized in Table 1. According to studies, families of conserved P-deficiency responsive miRNAs that includes miR156, miR159, miR166, miR319, miR395, miR398, miR399, miR447, and miR827 were commonly found in different studies and reported extensively (Sun et al., 2012; Sunkar et al., 2012). However, some of them were found upregulated such as miR156, miR399, miR778, miR827, miR2111, while specifically miR169, miR395, and miR398 exhibited suppressed expression during low $\mathrm{P}$ availability (Hsieh et al., 2009). Previous studies validated plethora of genes and their involvement to $P$ sensing, acquisition and allocation as reviewed in the past (Liang et al., 2014). Recently, plant miRNAs were under observation exclusively for their regulatory roles in nutrient homeostasis thereby targeting number of P-starvation related genes. The most studied phosphate responsive miRNA, miR399, which strongly induced under $P$ deficient conditions (Chiou et al., 2006; Phillips et al., 2007), however, a sharp decline in its expression was noticed immediately after readdition of $P$ during further assessment (Fujii et al., 2005). All the six members of MIR399 genes (MIR399A-F), in Arabidopsis, were upregulated during limited $P$ conditions (Kuo and Chiou, 2011). In Arabidopsis, overexpression of miR399, characterized by chlorosis and necrosis at the leaf tips, resulted due to the excessive accumulation of $P$ in plant shoots thereby enhanced $P$ uptake and its allocation to shoots (Aung et al., 2006; Chiou et al., 2006). Furthermore, the elevated accumulation of $P$ levels, increased intracellular acid phosphatase activity (Apase activity), as well as transformations in root morphology were observed in transgenic tomato overexpressing the Arabidopsis miR399 (Gao et al., 2010). During the previous reports, miR399 was significantly characterized to positively regulate $P$ uptake from plant roots and distribute to shoots under $P$ starvation, whereby targeting $\mathrm{P}$ transporter (PHT1;7), a DEAD box helicase and $\mathrm{PHO}$; which encodes ubiquitin-conjugating enzyme (UBC24; Allen et al. 2005).

The transcriptional activation of array of PS1 genes is critical for controlling signaling responses under $\mathrm{P}$ starvation. The PS1 genes are regulated by TFs including MYB, PHR1 and partially redundant TF PHL1 (PHR1-LIKE1; Bustos et al., 2010). In Arabidopsis, members of miR399 genes contain PHR1-binding sites PIBS (GNATATNC); a motif that is required for binding to most of $P$ - responsive genes and is critical for their transcriptional regulatory functions (Bari et al., 2006). Interestingly, other P-related cis elements such as PHR1, PHO-like, W-box, TATA-box and P-responsive elements were also found in the upstream promoter sites of
P-responsive miRNAs including miR399 (Zeng et al., 2010; Xu et al., 2013). Under P deficiency, Arabidopsis phr1 mutants showed significantly reduced expressions of miR399 as well as group of other $P$ related genes, while set of $P$ deficiency-responsive genes were found upregulated in pho2 mutants under sufficient $P$ availability, hence, concluded that PHR1 functions upstream of miR399 and PHO2, however, it is not the only element required for miR399 induction in P signaling network (Bari et al., 2006). Another recent report conducted by Baek et al. (2013), demonstrated that miR399f belongs to Arabidopsis, transcriptionally regulated by MYB TF induced in P-deprived plants thereby binding to a $M Y B$ binding-site present in the promoter region of miR399f. Previous compelling evidences demonstrated that miR399 act as positive regulator under $\mathrm{P}$ deficiency, while PHO2; a target gene for miR399, behave as negative regulator and inhibit $\mathrm{P}$ uptake under normal $\mathrm{P}$ concentrations (Lin et al., 2008; Yuan and Liu, 2008). Moreover, to maintain $\mathrm{P}$ homeostasis in plants, long-distance movement of miR399 through systemic repression of $\mathrm{PHO} 2$ from shoots to roots was also confirmed. Subsequently, multiple role of miR399 was substantially noticed in rice thereby its positive response to various nutrients. The results obtained through GeneChip analysis of the transgenic rice overexpressing OsmiR399, confirming the upregulation of several downstream genes participate in multiple nutrients stress i.e potassium, iron, sodium and calcium, however, the mechanisms of regulation vary for particular nutrient displayed by OsmiR399 (Hu et al., 2015). Interestingly, most studies in higher plants confirmed that miRNA targets at the cleaved sites showed near perfect complementarity with miRNA, however, in Arabidopsis, a non-protein gene IPS1 (Induced by phosphate starvation1), inhibits the miR399 activity, despite having sequence complementarity with miR399. Moreover, the IPSI evasion by not being degraded as a target of miR399, was due to a mismatched loop that significantly interrupted the pairing of IPS1-miR399 at the cleaved site. Consequently, this mechanism of "target mimicry" was also supported by noticing reduced $P$ levels in the shoots due to higher accumulation of $\mathrm{PHO} 2 \mathrm{mRNA}$ and its enhanced activity (Franco-Zorrilla et al., 2007). Thus the pseudo interaction between IPSI and miR399, represents unique insights into regulatory functions determined by its natural target mimicry, hence, identification of new endogenous target mimics will help us design more appropriate miRNAs-oriented strategies to cope nutrient stress responses in plants.

Beside the upregulation of miR399, the expression of miR827 also induced in $\mathrm{P}$ depleted Arabidopsis plants, however, miR827 specifically target NLA (nitrogen limitation adaptation) gene and suppressed its transcripts level up to 3-fold in overexpressing-miR827 plants. In Arabidopsis plants, it was reported that NLA (nitrogen limitation adaptation) gene responds to limited nitrogen level (Peng et al., 2007), however, the transcripts of NLA repressed in overexpressing-miR827 while induced in miR827 mutants, suggesting that NLA is a target of miR827 and $\mathrm{P}$ regulation by miR827 is nitrate dependent (Hsieh et al., 2009; Kant et al., 2011). Additionally, the nla mutant was characterized by its abnormal phenotype specifically under low $\mathrm{N}$, while showed similar growth to WT during sufficient $\mathrm{N}$ availability. To understand the molecular mechanisms behind this 
physiological aberrations, the idea of restoring the phenotype of nla mutants to WT thereby chemical based mutagenesis lead to the identification of $P$ transport related genes; PHF1 and PHT1 (Kant et al., 2011). Overaccumulation of $\mathrm{P}$ content exposed to low $\mathrm{N}$ conditions corresponds to early senescence of nla mutants, indicating crucial role of $N L A$ in $\mathrm{P}$ regulation in a nitrate dependent fashion. The NLA transcripts negatively regulated by miR827 and the $P$ toxicity displayed by overexpressing miR827 and nla mutant plants were consistent with similar $\mathrm{P}$ contents in mir827 mutant and in NLA-overexpressing plants (Kant et al., 2011). Similarly, pho2 mutants were also nitrate dependent, and displayed $\mathrm{P}$ toxicity related phenotype like the nla mutants. Nevertheless, compared with nla or pho2 single mutants, the excess accumulation of $P$ content was not observed in nla pho2 double mutant plants, which further explains that NLA and PHO2 might operate through same pathway mediated by miR827 and miR399 respectively, and play pivotal regulatory roles in P homeostasis (Kant et al., 2011). In rice, osa-miR827 was strongly induced under limited $P$ as detected by northern blot analysis. The results further demonstrated that it's two target genes OsSPX-MFS1 and OsSPX-MFS2; encodes SPX-MFS proteins, were differentially expressed under $P$ starvation. However, in overexpression miR827 and T-DNA knockout lines their expressions were downregulated and upregulated respectively, suggesting a complex mechanism of regulation of both the targets by miR827 (Lin et al., 2010). Similarly, another report (Wang et al., 2012), revealed the central regulation of miR827 by OsPHR2; a transcriptional factor involved in $\mathrm{P}$ homeostasis regulation in rice as previously described by Bustos et al. (2010), consequently, enhanced $P$ content observed in miR827 overexpressing plants or OSSPX-MFS1 mutants disclosed by minimizing $P$ remobilization from old to young leaves. Consequently, this report suggesting that coordinated regulation of $P$ homeostasis by miR827 and SPXMFS1 is required in leaves, thereby OsSPX-MFS1 being a potential $\mathrm{P}$ transporter.

In maize, two genotypes (wild type; Qi319, low P tolerant mutant; 99038) were analyzed by sRNA sequencing for the characterization of P-responsive miRNAs, which implicated dynamic expressions of several miRNAs under normal and limited P resistant genotypes (Pei et al., 2013). These findings suggested that low P-responsive miRNAs play crucial roles in determining the resistance level of low $P$ in different maize genotypes. Similarly, qRT-PCR and northern blot analysis in P-deprived wheat, demonstrated the upregulation of nine TaMIRs except TaMIR408; being the only one which repressed in response to low P supply (Zhao et al., 2013). Expression pattern of randomly selected target genes of the limited $\mathrm{P}$ associated miRNAs including $M Y B 3$ (TaMIR159b), ARF8 (TaMIR167), SBP (TaMIR408), NADH dehydrogenase subunit 6 (TaMIR1139), Annexin-like protein (TaMIR1125), Auxin-induced protein (TaMIR1135) and PWWP domain containing TF (TaMIR1136), were also found inversely correlated with their corresponding TaMIRs.

In soybean, micro-array based transcriptional analysis revealed significant upregulation of 15 miRNAs, while 23 were found suppressed during distinct $P$ regime in leaves and roots of the plant (Zeng et al., 2010). The results showed that miR159a upregulated during $P$ deficiency especially in roots; conversely, downregulation of miR319a, miR396a, miR398b, miR1507a has been validated through qRT-PCR.
Moreover, TATA-box and transcription start sites (TSSs) were located in the upstream regions of most of the P-responsive miRNAs, however, in total 125 putative cis elements were found including signaling, metabolism, transport and stress-related. This might target the regulation of several genes involved in diverse signaling pathways that ultimately modulate numerous physiological functions in plants. In conclusion, a great number of $\mathrm{P}$ deficiency related miRNAs were identified using micro-array, SRNA, and degradome sequencing technologies, northern blot, and qRT-PCR analysis in various plant species including white lupin (Zhu et al., 2010), common bean (Valdes-Lopez et al., 2010), tomato (Gu et al., 2010), as well as barley (Hackenberg et al., 2013), implying that they are coordinately involved in the conserved $\mathrm{P}$ signaling pathways in plants.

\section{Potassium and plant miRNAs}

Potassium (K) is a vital nutritional element in plant growth and development, and considered as third essential macronutrient after nitrogen and phosphorous. Potassium (K) plays major biochemical and biophysical roles in plants including enzyme activation, membrane transport, anion neutralization, photosynthesis, osmoregulation, protein synthesis, stomatal movement, energy transfer (Marschner, 1995), as well as numerous stress resistance such as salinity, drought, cold, high light, and hormones (Bose et al., 2014; Zorb et al., 2014; Straltsova et al., 2014; Daras et al., 2015). Moreover, a number of studies demonstrate that unavailability of $\mathrm{K}$ content in most soils can adversely affect physiological and morphological aspects of the plant, thus negatively influence the crop production (Oosterhuis et al., 2013). Therefore, plants need to activate sophisticated $K$ sensing and signaling network in order to modulate responses in limited $\mathrm{K}$ conditions. Consequently, plants trigger the expression of high-affinity $\mathrm{K}$ transporters and up-regulate certain $\mathrm{K}$ channel genes to facilitate uptake and transport of this cation (Adams and Shin, 2014). Similar to the other macronutrients such as $\mathrm{N} \mathrm{P}$, the $\mathrm{K}$ uptake into plant roots has high and low-affinity components (Nieves-Cordones et al., 2014). A substantial number of studies validated $K T / H A K / K U P$ family members and named as HAK1 or HAK5 (in some species), which consist the high affinity $\mathrm{K}$ uptake system in different plant species (Martínez-Cordero et al., 2004; Nieves-Cordones et al., 2007). In case of low-affinity $\mathrm{K}$ uptake system, an inwardly-rectifying $\mathrm{K}$ channel of the Shaker family, AKT1, has been identified in many plant species (Fuchs et al., 2005; Lebaudy et al., 2007). In response to the external $K$ fluctuations, plant root cells able to sense the extracellular $\mathrm{K}$ concentration and generate initial $\mathrm{K}$ signaling events, consequently, triggers bunch of morphological and physiological responses to fine tune the absorption, transport, and efficient use of $\mathrm{K}$ to overcome deprived conditions (Cherel et al., 2014). In K-deprived conditions, the downstream components such as ROS (Shin et al., 2005), $\mathrm{Ca}^{2}$ + sensors (Xu et al., 2006), transcription factors, e.g., an AP2/ERF class TF RAP2.11 (Kim et al., 2012), are actively involved in channeling the transport of $\mathrm{K}$ ion to different locations depending on where they are functional. In K-deficient conditions, signals are decoded by cytoplasmic sensors followed by regulation at transcriptional and post-translational level to adjust both physiological and 
biochemical responses (Wang and $\mathrm{Wu}, 2013$ ). A previous study conducted by Yan et al. (2014), showed that miR444a was uniquely involved in $\mathrm{K}$ signaling during limited $\mathrm{K}$ in rice plants, which slightly reduced the expression of this miRNA. Moreover, it has demonstrated diverse roles in rice plants and was involved in a complex interaction between the $\mathrm{NO}_{3}$ and P-signaling pathways. Additionally, over-accumulation of both $\mathrm{N}$ and $\mathrm{P}$ was noticed in mi444a-overexpressing plants. Further, it affects the root architecture both under $\mathrm{N}$ and $P$ limiting conditions, also, the root performances of miR444a-overexpressing rice plants under $\mathrm{P}$ starvation were similar to plants grown under high nitrate conditions. These findings suggested that miR444a regulates P-starvationinduced root architecture possibly via activation of the miR444a-regulated $\mathrm{NO}_{3}{ }^{-}$signaling pathway (Yan et al., 2014). Furthermore, the authors also noticed the reduced nitrate induced lateral root growth in rice caused by suppression of its target MADS-box genes; a family of TFs associated with several developmental regulatory pathways from root to flower and fruit development (Becker and Theißen, 2003). These observations indicated that miR444a participates in the $\mathrm{NO}_{3}{ }^{-}$signaling pathway to trigger plasticity of lateral root development. Role of miR167 in K signaling could also be investigated for further studies, which is another conserved plant miRNA that putatively targets the ion transporters genes (Griffiths-Jones et al., 2006; Zhang Q et al., 2013). In rice, miR167 putatively targets intracellular trafficking and vesicular transport genes ( $\mathrm{Xu}$ et al., 2014). An interesting competing phenomenon was noticed for $\mathrm{NH}_{4}{ }^{+}$and $\mathrm{K}$ uptake at the site of transporters in barley and Arabidopsis (ten Hoopen et al., 2010), which explains the possibility of miRNA regulation for maintaining nutrients homeostasis. Moreover, HAK5 transporter favors $\mathrm{N}$ uptake in the presence of $\mathrm{NH}_{4}{ }^{+}$in $\mathrm{K}$ containing medium (ten Hoopen et al., 2010). Similarly, the high affinity protein AKT1 acts as main transporter for $\mathrm{K}$ uptake even in low $\mathrm{K}$ concentrations. Importantly, in silico analysis can reveal some crucial transporter proteins involved in Kuptake and mobilization such as $A K T, H A K$, and $H K T$, which acts as potential target sites for miRNAs based regulation. However, multiple roles for nutrients sensing, uptake and transport regulated by miRNAs in order to fine tune physiological state of the plant still requires extensive knowledge at various levels.

\section{Sulfur and plant miRNAs}

The availability of the macronutrient sulfur (S), an indispensable inorganic mineral, is crucial for plant growth and development, eventually determining plant vigor and yield. Sulfur is usually taken up as sulfate $\left(\mathrm{SO}_{4}{ }^{2-}\right)$ by the root system, and is then transported to the shoot via the xylem. $\mathrm{S}$ in its absorbable form $\left(\mathrm{SO}_{4}{ }^{2-}\right)$ is taken up from the soil through sulfate transporters (SULTRS), which are located in epidermal and cortical plasma membrane of root. In Arabidopsis, a total of 14 putative sulfate transporters have been identified, out of which high-affinity sulfate transporters such as SULTR1;1 and SULTR1;2 are chiefly involved in $\mathrm{SO}_{4}{ }^{2-}$ uptake from soil. Whereas, low-affinity sulfate transporters (SULTR2;1, SULTR2;2, and SULTR3;5) facilitate $\mathrm{SO}_{4}{ }^{2-}$ translocation within the plant (Kataoka et al., 2004). Cysteine is a main precursor molecule for various S-containing compounds including glutathione, phytochelatins, and metallothioneins, which are well recognized for their involvement in numerous plant stress tolerance (Gill et al., 2013; Anjum et al., 2015).

Depending on the $S$ availability i.e. limited or in abundance, the expression of several $\mathrm{S}$ transporters is largely regulated by miR395. However, the different tissue specific expression corroborated a positive correlation between target mRNA (SULTR2;1) and miR395 levels in roots, whereas a negative spatial correlation between them was noticed in shoots (Kawashima et al., 2009). Another intriguing study performed by Liang et al. (2010), showed that miR395 induced during $S$ deprivation and its main targets were two families of genes, APS and SULTR2;1, which play role in $S$ metabolism. In miR395 overexpressing transgenic Arabidopsis, three APS genes were suppressed and resulted in the overaccumulation of $S$ in the shoot. On the other hand, the expression of SULTR2 ; 1 was downregulated which disrupted the transport of $\mathrm{S}$ from mature to young leaves, thus, substantiate the evidence of regulating $\mathrm{S}$ homeostasis in Arabidopsis under S deficiency. Also, the expression of miR395 induced in the absence of APS4 gene, which confirmed its negative feedback regulation. Consequently, this process alters the regulation other target genes and further complicates S metabolism (Liang et al., 2010). The translocation of $S$ ions from the root towards the shoot was facilitated by restricted SULTR2;1 expression in the xylem parenchyma controlled by miR395. Importantly, during limited S condition, induction of miR395 is dependent on SLIM1, a key transcription factor in the $S$ assimilation pathway, which is critical for the increased translocation of sulfate to the shoots, so as to enable more efficient sulfate assimilation in the leaves (Kawashima et al., 2011). During limited S condition, miR395 was strongly upregulated and suppressed its target ATP sulfurylase genes, such as APS1, APS3, and APS4, which confirmed the involvement of miR395 in S assimilation regulatory circuits apart from SLIM1 dependent mechanism (Matthewman et al., 2012). Several other S-deficiency related miRNAs were identified in Brassica napus such as miR156, miR159, miR160, miR164, miR167, miR168, miR394 and miR395, which could facilitate us to understand underlying regulatory mechanisms of miRNAs during S deprivation (Huang et al., 2010).

\section{MiRNAs responsive to mineral elements $(\mathrm{Cu}, \mathrm{Zn}, \mathrm{Fe}, \mathrm{Mn}, \mathrm{B})$}

Copper (Cu), Zinc (Zn), Iron (Fe), Manganese (Mn), Boron (B), all are imperative for most of the growth and developmental stages of higher plants (Hansch and Mendel, 2009). Cu plays important roles in plant cellular processes and slight $\mathrm{Cu}$ deficiencies could seriously affect plant growth and overall biomass (Shin and Yeh, 2012). Fe deficiency causes retarded vegetative growth and marked yield and quality losses (Abadía et al., 2011), whereas $\mathrm{Zn}$, being a structural component of numerous proteins, affects fundamental physiological processes under its limited availability in plants (Mattiello et al., 2015). Functions of B are largely associated with meristematic tissues, hence, its deficiency principally affects actively growing organs such as shoot and root tips (Hansch and Mendel, 2009). Whereas $\mathrm{Mn}$ is involved in the biosynthesis of lignin polymerization, therefore $\mathrm{Mn}$ deficiency causes reductions in lignin concentrations in plants and particularly in roots (Schmidt et al., 2016).

Under limited Cu availability in plants, the miR398 directed the suppression of $\mathrm{Cu} / \mathrm{Zn}$ superoxide dismutases (SOD) 
genes, CSD1, CSD2 and Cu chaperone for SOD (CCS1), which is essential for generating the mature SODs, thus implying the important role of miR398 to fine tune posttranscriptional regulation (Sunkar et al., 2006; Beauclair et al., 2010). Also, a subunit of cytochrome $C$ oxidase, a mitochondrian protein encoded by CYCLO MONOOXYGENASE is downregulated by miR398. Further, other three miRNAs in Arabidopsis, miR397, miR408, and miR857 were accumulated during limited $\mathrm{Cu}$ supply, consequently, downregulated the expression of its targets, laccase and plastocyanin genes, thus ensuring the copper supply to the plants under its limited availability (Abdel-Ghany and Pilon, 2008). Among laccase (LAC) genes, $L A C 3, L A C 12$, and $L A C 13$, are suppressed by miR408, whereas miR397 targets the mRNA of LAC2, LAC4, and LAC17, however, miR857 was involved primarily to degrade the transcript of LAC7. Importantly, miRNAs mediated targeting of $\mathrm{Cu}$ proteins for the regulation of $\mathrm{Cu}$ homeostasis seems strikingly unique mechanism, which is different for other trace elements thereby targeting the machinery required for their assimilation.

Several miRNAs were identified during $\mathrm{Mn}$ starvation, which were also involved in other nutrient stresses (Table 1). A study performed by Valdes-Lopez et al. (2010), identified Mn-responsive miRNAs in common bean such as miR156, miR157, miR166, miR167, miR169, miR170, miR172, miR319, miR390, miR395, miR2118, miR1508, miR1526, miR1532 and miR2118. The targets for these miRNAs were identified to be associated with wide range of TFs and other regulatory proteins. However, this report also demonstrated that the changes in the supply of one nutrient affect the availability of other nutrient elements, which explains the possibility of complex interaction between miRNAs in regulating nutrient homeostasis. For instance, regulation of miR398 was involved during $\mathrm{Cu}$ deficiency by activating the expression of CSD gene, while its opposite regulation was noticed in case of Fe deficiency (Waters et al., 2012). Under Fe starvation, miR397, miR398a, miR398b, miR398c, miR398s, miR399, miR408 were suppressed, while limited $\mathrm{Cu}$ induced their expressions. In addition, FeSODs are downregulated and the proteins are functionally replaced by CUSODs by increased expression of CSD1 and CSD2 under Fe starvation, which suggests a coordinated regulation of miRNAs and CUSODs to maintain Fe homeostasis (Waters et al., 2012). Moreover, other conserved miRNAs families were also identified in Arabidopsis under Fe starvation, such as miR159, miR164, miR172, miR173, and miR394 (Kong and Yang 2010). Interestingly, Fe-responsive cis regulatory elements (IDE1/IDE2) were also found in the promoter of these miRNAs, which are crucial for the regulation of Fe-deficiency responsive genes. Further other types of cis elements were also found in this study, which demonstrate the involvement of various biochemical and metabolic pathways during $\mathrm{Fe}$ homeostasis. In case of Zn deficiency, several miRNA families were upregulated in root of Sorghum bicolor that include miR398, miR319, miR166, miR168, and miR399, while miR171 family and miR528 were significantly downregulated in leaves (Li et al., 2013). Target genes were predicted for these $\mathrm{Zn}$-responsive miRNAs, most of which encoded for TFs and proteins associated with metabolic processes, such as TCP2-1, TCP2-2, SCL6-IV, Plantacyanin, CSD2, PHB-1, and $P H B-2$. This study strongly suggested that miRNAs play an important role in $\mathrm{Zn}$-deficiency tolerance in Sorghum and highlighted a novel molecular mechanism of Zn-deficiency resistance in plants. In case of B deficiency, control and B-deficient root libraries were generated in Citrus sinensis for miRNAs identification and expression pattern analysis. In roots subjected to $B$ starvation, 52 miRNAs were found with elevated expressions, while 82 were found downregulated, demonstrating marked flexibility of $C$.sinensis roots during B deficiency tolerance (Lu et al., 2014). This study also proposed several adaptation strategies of $C$. sinensis roots for B-deficiency tolerance based on the their results, mainly includes (1) perturbation of ROS signaling and scavenging due to elevated expression of miR474 and suppression of miR782 and miR843; (2) modifications in the lateral roots development in $C$. sinensis due to suppression of miR5023, which might upregulated its target gene expression ROOT HAIR DEFECTIVE3 (RHD3), which was previously reported as key factor involved in increase lateral roots formation in plants (Hajiboland et al., 2012); (3) upregulation of miR394 in roots possibly downregulated the accumulation of $L E A F$ CURLING RESPONSIVE (LCR) MRNA, which lead to certain morphological changes specifically required for B-deficiency tolerance; (4) downregulation of miR830, miR5266 and miR3465 increased cell transport in vesicles and organelles by altering the expression of targets such as microtubule motor proteins (Kinesins) and autoinhibited $\mathrm{Ca}^{2+}$-ATPase 11; (5) increased the transcript of miR821 might suppressed its target gene (GDH1; NADP-dependent glutamate dehydrogenase), while decreased transcript of miR5023 in roots, conceivably altered several metabolic reactions due to targeting FK506-binding proteins (FKBP), cyclosporins (CyPs) and parvulin $(P \vee n)$ which are the three major classes of peptidyl prolyl cis-trans isomerases (PPlases) and are considered to assist chaperones by accelerating the slow rate-limiting isomerization steps. Therefore, understanding miRNAs-based strategies in B-deficient roots would further elucidate underlying molecular mechanisms necessary for maintaining nutrients in plants. However, miRNAs-based regulation of nutrients homeostasis in various plants exhibited a number of similar adaptations at the morphological, physiological and molecular level. Among them, the most critical strategies including but not limited to the following adaptations, such as root architecture modifications for nutrient acquisition, modulation of nutrient transport channel, long distance signaling and mobility under nutrients starvation conditions as well as the involvement of plant hormones at various levels during this process, details of which are provided in our next section. Nevertheless, all of these events have expanded our understanding for the underlying precise control mainly at transcriptional and posttranscriptional levels and will help us fine tune future endeavors.

\section{MiRNAs-mediated plant adaptation under nutrient stress}

\section{Root architecture modifications to optimize nutrient acquisition}

Plant roots play highly important roles ranging from anchorage and acquisition of nutrients and water to interactions with microsymbionts in the soil. Heterogeneously distributed soil resources valuable for the plant productivity is mainly determined by root ability to 
acquire them through its widely spread root system. Root architecture defines the shape and spatial structure of the entire root system and it depends on both the primary and lateral root growth (size) as well as branching of the lateral roots (shape). However, the ability of nutrient uptake may not be solely due to differences in root size, but also depends on nutrient uptake kinetics that define root functioning (Pang et al., 2015). Further, plant root architecture is controlled by several well-described signalling pathways, which are notably linked to hormone action (Mansoorkhani et al., 2014). Root tissues are generated by the root apical meristem (RAM), representing a radial patterning that consists of concentric cell layers of epidermis, cortex, endodermis and pericycle, which encapsulates the surrounding region of xylem and phloem. Cell division and elongation in the RAM is controlled by the coordinate action of various phytohormones, such as auxin, cytokinin, ethylene, and gibberellins (Benkova and Hejatko, 2009; Perilli et al., 2012). In this context, numerous miRNAs were reported to be involved during root development thereby controlling cell division and differentiation, consequently alters the entire geotropical status of the plant roots in terms of nutrient procurement. For instance, miRNA160 that repressed the expression of its targets ARF10 and ARF16, known as AUXIN RESPONSE FACTORS (ARFS) that control cell division and differentiation in the RAM, showed shorter roots with enlarged tumour like root apex, demonstrated that miR160 and its $A R F$ targets may be necessary to restrict cell divisions and to promote cell elongation and differentiation during the root cap formation (Wang et al., 2005). In Arabidopsis, another crucial report forwarded by Rodriguez et al. (2016), studied the involvement of miR396 in the root elongation and control of transit-amplifying cells at the root meristem by targeting GROWTH-REGULATING FACTORS (GRFs), however, authors elegantly deciphered an miR396/GRFs-PLT regulatory module to balance the division activities in this territory. Another equally interesting study demonstrated that miR171 overexpression reduces the primary root length, similar phenotypes were observed for subsequent mutation in the HAM genes culminated in abnormal columella cells with arrested root growth as described in earlier studies (Engstromet al., 2011; Zhou et al., 2015). Despite their critical roles during embryogenesis, miRNAs also play vital roles in overall root development, such as miR165/166 regulate differentiation of the vascular tissues and control the root meristem size (Carlsbecker et al., 2010). Further, a negative role of miR857 was reported by Zhao et al. (2015), showing its negative regulation during differentiation of secondary xylem. Importantly, expression of miR390 in pericycle cells during lateral root development, negatively regulated auxin associated TFs including ARF2, $A R F 3$ and $A R F 4$ in lateral root primordia, thus suggesting its strong involvement in controlling lateral root growth (Marin et al., 2010). Moreover, miR164 participated during the adaptation process of root architecture under nutrient deficient conditions and significantly increased lateral root development (Li et al., 2012). Interestingly, miR393 was specifically induced in the roots and increased the lateral roots by modulating auxin signaling (Windels et al., 2014). Another detailed study reported by Gutierrez et al. (2012), demonstrated the coordinated roles of miR160 and miR167 targeting auxin responsive genes indispensable for root architecture remodeling. Similarly, overexpression of
miR847 exhibited more lateral roots thereby modulating indole acetic acid (IAA) related genes (Wang and Guo, 2015). Plants respond according to the availability status of macroand micro- nutrients and in turn adapt certain strategies at the molecular level in order to efficiently use available resources. Several miRNAs participate at this level for nutrient uptake, translocation, sensing and assimilation via modifications in its root architecture thereby targeting plethora of genes and alter their expression (Figure 2). However, number of factors at all the aforementioned levels contributes to the regulation of root architecture development, such as preinitiation and meristem activation as well as hormonal switches (Petricka et al., 2012; Lavenus et al., 2013). Moreover, nutrients stress trigger several miRNAs to regulate the entire process of efficient nutrient acquisition, however, phytohormones and nutrient-specific transporter proteins actively participate at this level (Figure 2). However, nutrients intake by plants through its root system is one of the crucial events during this process and further understanding the control of root architecture by miRNAs under nutrient deficient conditions is indispensable.

\section{Modulation of the plant transport channel}

The uptake of plant essential nutrients rely upon soluble/chemical form of each nutrient element, which is greatly affected by number of environmental factors including but not limited to water gradient in the soil, soil and water $\mathrm{pH}$, redox potential, availability of microbes, and distribution of organic matter in soils (Marschner, 2011). In fact, nutrient availability through soils is often limited due to its highly heterogeneous environment, which changes readily over time and enormously affects nutrients mobility. These factors, including nutrients mobility, consequently result in spatio-temporal distributions of soil nutrients (Jobbagy and Jackson, 2001). Thus, plants being sessile in nature must cope these sorts of remarkable changes thereby sophisticated adaptations for optimal nutrient procurement. Modulation of nutrient transport channel is one such effective strategy, which ensures optimal nutrient availability to the plants for survival. However, coordinated action of transport molecules including transporter proteins, transcription factors and various sensing and signaling related molecules play their crucial roles in this complex mechanism (Figure 3). Mainly, transport process includes uptake of nutrients from soil through root cells with subsequent loading onto xylem tissues, finally, mobilization and reallocation from source to sink occurs in a meticulous manner. In recent years, several novel players were identified for the transport of distinct nutrient elements including N, P, K, S and other mineral elements. Generally, N uptake and transport involves four major transporter families that includes, NITRATE TRANSPORTER 2 (NRT2), NITRATE TRANSPORTER 1/PEPTIDE TRANSPORTER FAMILY (NPF), CHLORIDE CHANNEL FAMILY (CLC) and SLOW ANION ASSOCIATED CHANNEL HOMOLOG (SLAC/SLAH) transporters (Negi et al., 2008; Barbier-Brygoo et al., 2011; Krapp et al., 2014; Léran et al., 2014). Interestingly, high-affinity nitrate transporters, NRT2.4 and NRT2.5, which uptake nitrate into the roots in addition to its participation in shoot transport, and also interact with NRT2.1 to maintain nitrate in the phloem under $\mathrm{N}$ deficiency (Lezhneva et al., 2014). Similarly, for the $\mathrm{P}$ uptake and mobility, $\mathrm{P}$ high-affinity transporters 
(PHTs) and $\mathrm{P} / \mathrm{H}^{+}$symporters have been identified (Mlodzinska and Zboinska, 2016). In Arabidopsis, PHT gene family is divided into four groups (PHT1, PHT2, PHT3, and PHT4), which participated at distinct levels for $P$ mobilization (Nussaume et al., 2011; Ye et al., 2015). Other P transporters such as PHO1 (Phosphate 1), involved in P loading into the xylem, and $\mathrm{PHO} 2$ (Phosphate 2), which degrades phosphate transporters (PHT1;1, PHT1;2, PHT1;3, PHT1;4, PHO1) and phosphate transporter facilitator1 (PHF1), thus play role as a negative regulator of $P$ uptake (Huang et al., 2013; Wege et al., 2016). In case of $K$ transporters, several gene families, including $K U P / H A K / K T, H K T, N H X$, and $C H X$ comprising the $K$ transport channel, however, these activities are coupled with $\mathrm{H}^{+}$or $\mathrm{Na}^{+}$co-transporters as reviewed by Wang and $\mathrm{Wu}$, (2013). In addition, an unknown K uptake pathway has also been proposed, which is distinct than that mediated by HAK5 and AKT1 (Caballero et al., 2012). In case of S, five groups of $S$ transporters have been characterized in Arabidopsis based on sequence similarity, substrate specificity and tissue specific localization, where members belonging to group 1 are high affinity $S$ transporters and group 2 are low affinity $S$ transporters (Yoshimoto et al., 2007; Takahashi, 2010). In case of micronutrients, such as Fe-regulated transporters (AtIRT1, AtIRT2, AtIRT3), and Cu transporters (COPT/Ctr-family), have been identified which play vital roles in $\mathrm{Fe}$ and $\mathrm{Cu}$ acquisition and transport (Andres-Colas et al., 2010; Barberon et al., 2011). In case of $\mathrm{Mn}$, which serves as a cofactor for essential plant processes, several gene transporter families have been implicated, including NRAMP (natural resistance associated macrophage protein), YSL (yellow stripe-like), ZIP (zinc regulated transporter/iron-regulated transporter [ZRT/IRT1]-related protein), CAX (cation exchanger), CCX (calcium cation exchangers), CDF/MTP (cation diffusion facilitator/metal tolerance protein), P-type ATPases and VIT (vacuolar iron transporter; Socha and Guerinot, 2014).

In recent past, miRNAs were extensively explored during nutrient deficient conditions, which were involved in modulating the expression of genes encoding specific group of transporters, however, number of other gene families (especially transcription factors) were also involved in overall miRNAs-mediated modulation of nutrient transport channels. For instance, miRNA156 targets SPL3, SPL9, and $S P L 15$, members belonging to SPL gene family of TFs, which inhibits vegetative phase of the plants, thus play critical roles in maintaining normal growth during limited $\mathrm{N}$ conditions (Krapp et al., 2011). Moreover, miR393 functionally targets Auxin Signaling F-Box Protein 3 (AFB3) in roots, and in this study authors also found that $\mathrm{N}$-responsive miR393/ARF3 module is necessary to repress primary root while induce lateral root formation (Vidal et al., 2010). Other auxin responsive factors, such as $A R F 16$ and ARF8, targeted by miR160 and miR167, respectively were found to be involved in controlling the root architecture under limited $\mathrm{N}$ conditions (Gifford et al., 2008; Liang et al., 2012). Further, an N-responsive miRNA, miR171, downregulated its targets SCL6-II, SCL6-III, SCL6-IV, members of the Scarecrow-Like 6 (SCL6) gene family, and authors found their strong association with root elongation (Liang et al., 2012). Other miRNAs and their targets involved in $\mathrm{N}$ transport channel includes, miR444 (targets, OsMADS23, OsMADS27a, OsMADS27b, and OsMADS57; MADS-Box genes) in rice (Yan et al., 2014), while miR169 (targets, NFYA3, NFYA5, and
NFYA8; members of transcription factor NFYA family), interestingly, NFYA were involved in the regulation of $N$ transporters NRT1 and NRT2 (Zhao et al., 2011). Similarly, a set of specific miRNAs and their targets were also found compulsory for $\mathrm{P}$ regulation under its limited supply. Two phosphate transporters; phosphate transporter 1 (PHT1) and phosphate 1 (PHO1), core proteins necessary for $\mathrm{P}$ assimilation and translocation, are directly or indirectly regulated by miR399 and miR827 under P stress (Liu et al., 2012). However, a negative regulation of nitrogen limitation adaptation (NLA) gene, a target of miR827, was also necessary to maintain $\mathrm{P}$ homeostasis in $\mathrm{N}$ dependent manner (Kant et al., 2011). In case of $S$ stress, the induction of miR395 confined the expression of SULTR2;1, which is a low affinity sulfate transporter, and consequently facilitates the translocation of sulfate ions from the roots to the shoots. More importantly, accumulation of SULFUR LIMITATION1 (SLIM1) protein in the roots triggers other $S$ transporters to facilitate this process during $S$ deficiency (Kawashima et al., 2011). Moreover, miR395 also triggers $S$ assimilation thereby regulating ATP sulfurylase genes, such as APS1, APS3, and APS4 (Matthewman et al., 2012). In case of Cu starvation, miR397, miR408, and miR857 were upregulated and thier targets were associated with laccase and plastocyanin gene families. Numerous other miRNAs were responsive to various other metal ions, such as $\mathrm{Al}, \mathrm{As}, \mathrm{Hg}, \mathrm{Cd}$ and $\mathrm{Cs}$ toxicity, thereby altering the expression of plethora of stress related genes (Zeng et al., 2012; Zhou et al., 2012a, 2012b; Zhang et al., 2013; Yang and Chen, 2013; Jung et al., 2015). The main idea of describing the dynamic regulatory roles of miRNAs during various nutrient stresses thereby targeting wide array of stress associated genes including transporters, was to establish the fact that miRNAs are critically involved at every step for maintaining the nutrient homeostasis; however, finding the upstream regulatory elements in this highly complex mechanism is still elusive.

\section{Phloem-specific miRNAs and long distance nutrient mobility}

The requirement of essential inorganic nutrients inside cells and organs are tightly regulated in order to maintain nutrients homeostasis in plants, however, the transfer of information for nutritional needs between organs and across all plants parts is also crucial for optimized nutrient allocation, specifically in developing tissues and organs of the plants. Any organ under nutrient deficient condition needs to convey this message to other organs, whether for nutrient reallocation or uptake. This kind of cross-communication and translocation is regulated via phloem, which are conducting tissues that originate from vascular meristem within the vascular bundle. The process of nutrients mobility starts after its uptake by roots. Nutrients are then allocated to farther storage parts or according to its demand in various organs comprising long distant systemic mobility. Both xylem and phloem participate in long-distance mobility (Figure 3); however, phloem-mediated signaling and translocation play important roles during nutrient stress conditions. The Phloem maintains the source and sink connection as well as ensures the signal transduction during various stress responses. Recently, phloem specific miRNAs suggested their regulatory roles in establishing gradients of gene expression necessary 
for signaling involved in diverse physiological feedbacks, including nutrient transport under its short supply (Kehr, 2013). In this context, a study conducted by Buhtz et al. (2010), identified phloem associated miRNAs that responded specifically during nutrient deficiencies and this response was clearly dissimilar from that in the stem, roots and leaves. Authors found that miRNAs, such as miR162, miR167, miR168, miR169, and miR399 were strongly accumulated in phloem samples, while miR158, 396 and 397 were stem-enriched. Moreover, phloem specific miRNAs were also found distinct from that of leaf and roots, such as miR169, miR390, miR829, miR894 were more abundant in phloem sap, while miR156, miR159, miR160, miR162, miR164, miR165, miR166, miR167, miR393, miR394, miR396 and miR403 were less abundant in the phloem as compared to both leaves and roots. Further, phloem associated miR395 and miR399, transported from shoot to root via phloem, and that this translocation leads to a reduction of the amount of their target mRNAs in roots, revealed during grafting experiments. However, not all miRNAs are phloem translocatable, as seen in the case of miR171, which did not move. Therefore, miR395 and miR399 not only demonstrated translocation from source to sink but also controls the target gene expression in sink, thus act as scrupulous signaling molecules potentially involved during long distance transport (Figure 2). Interestingly, miR395, miR399 and miR2111 found in phloem sap, potentially characterized in long distance transport and were simultaneously responsive to diverse nutrients deficiencies (Abdel-Ghany and Pilon, 2008; Pant et al., 2008; Buhtz et al., 2010). However, nutrient sensing and signaling necessary for nutrients homeostasis, is a complex mechanism that requires large scale metabolic perturbations at multiple levels and phytohormones play crucial role in this process.

\section{MiRNAs and hormonal coordinated regulation of nutrient homeostasis}

To maintain optimal plant growth and development under limited availability of nutrients, plants undergoes numerous physiological and biochemical changes to maximize nutrients acquisition for its survival. Interestingly, nutrient elements serve as signaling molecules that integrates and coordinates gene expressions, triggers chemical switches and in turn stabilize plant metabolism and growth (Liu et al., 2017). Primarily these responses also activate highly sophisticated transport system that facilitate nutrients sensing, uptake and remobilization (Noguero and Lacombe, 2016). Nonetheless, plant hormones play central role during these events and interacts with nutrient signaling at multiple levels (Rubio et al., 2009). Recently, a large body of evidences reported the capability of miRNAs in the regulation of fundamental plant developmental processes, such as leaf morphogenesis, postembryonic shoot meristem regulation, root system development along with dynamic regulation of key agronomic traits in crop plants, as thoroughly reviewed by other colleagues (Rodriguez et al., 2016; Li and Zhang, 2016). In the context of nutrients homeostasis in plants, a tightly coordinated mechanism between miRNAs and various hormones has been observed, whereas miRNAs targeted phytohormones-associated genes corroborate this dynamic regulation; however, it is highly dependent on the level of nutrients availability to plants (Krouk et al., 2011). To control nutritional status in plants, several hormones are involved, such as CK, ABA, ET, AUX, JA and GA. Explicit hormonal control is indispensable, specifically in conjunction with root architecture regulation, such as lateral root development (Figure 2). Further, phytohormones interaction with nutrient signaling implicate complex physiological and biochemical changes that enhance nutrient scavenging and remobilization capacity, ultimately protect plants from the stress generated by nutrient deficiency as reviewed by Rubio et al. (2009). Interestingly, several MIR genes were found to contain hormone and stress responsive cis elements in their promoters (Zhao and Li, 2013; Chen et al., 2016).

Moreover, numerous miRNAs were functionally associated with various plant hormones exhibited by abnormal phenotypic changes in plants due to their hypersensitivity, which suggest that miRNAs are key regulators of hormones based responses in plants that affects their perception, distribution and metabolism (Liu et al., 2009). Among all the studied hormones in conjunction with miRNAs based responses for nutrient stress, auxin and cytokinins are the two most prominent groups of hormones involved in this mechanism. Several miRNAs are involved in hormones mediated responses, such as miR160 affect later roots formation via auxin signaling pathway thereby targeting auxin responsive factor (ARF18) in rice (Huang et al., 2016). Further, miR847 and miR390 controls lateral root development in Arabidopsis and it was regulated via auxin-dependent pathway (Yoon et al., 2010; Wang and Guo, 2015). Interestingly, auxin responsive factors, GmARF8a and GmARF8b, necessary for lateral root formation and nodules development were directed by miR167 regulation in soybean (Wang et al., 2015). More importantly, several evidence have indicated that ethylene promotes auxin biosynthesis and transport to regulate root development (Swarup et al., 2007; Stepanova and Alonso, 2009). Interestingly, miR399 was involved in ethylene systemic signaling pathway to regulate root development (Song and Liu, 2015). Further, a study in Arabidopsis reported by Iglesias et al. (2014), demonstrated that miR393 is involved in the downregulation of TIR1 and AFB2, a family of F-box receptors, which consequently repressed auxin signaling pathway and affected the plant root architecture. Also, ectopic expression of miR160 resulted in auxin and cytokinin hypersensitivity during symbiotic nodule formation and development in soybean; however, this regulation was largely developmental stage specific which was necessary for proper nodule formation and maturation (Turner et al., 2013; Nizampatnam et al., 2015). Moreover, the interaction between auxin and cytokinin is common in plant development, also, miR160 directed regulation of ARF10 provides a molecular link between auxin and cytokinin (Liu et al., 2016). Another interesting report described by Ariel et al. (2012), clearly established that miR171 was uniquely involved in the posttranscriptional regulation of NSP2, a well-known upstream TF that controls nodules development (Madsen et al., 2010), and that the cytokinins dependent dynamic regulation of NSP2 was mediated by miR171. The evidence collected under experimental observations markedly shows that miRNAs that target TIR1 and several $A R F s$ are affected by nutrient deficiency and wide range of other stresses, clearly implying that miRNAs play critical role during auxin regulations in response to plenty of environmental stress cues. For instance, the change in the 
expression levels of three miRNAs, miR160, miR167, and miR393 were observed during ABA application and exposure to various other abiotic factors such as salt, drought, cold, heat, including $S$ metabolism in a range of plant species, interestingly, the same three miRNAs are also induced in response to bacterial infection (Zhang et al., 2011). Moreover, previous reports revealed that the effects of miR160, miR166, miR167, and miR393 on auxin signaling might lie at the level of regulation of ARFs, additionally, auxin responsive elements (AuxREs) are often present in the promoters of miRNA genes such as miR167 (Meng et al., 2010). These findings suggest that feedback regulatory mechanism for auxin signaling and other signal transduction pathways might be controlled by miRNAs. Regardless of how these specific events are controlled and what are the upstream key players, regulation of miRNAs and its coordination with hormonal, nutritional, and stress signaling pathways is essential for plants in order to activate appropriate defense schemes.

\section{Conclusion and future perspectives}

Plants being naturally sessile therefore have evolved convoluted mechanisms to overcome nutrient stress conditions. More recently, miRNAs and their imperative roles during nutrient homeostasis have been extensively investigated, which encompasses all levels of nutrient acquisition that ranges from nutrient uptake, assimilation to mobilization/reallocation from source to sink. It is extremely desired to understand the science behind nutrient-plant synergy, and subsequently shrunken the usage of chemical fertilizers causing negative implications on existing ecosystem. Our current understanding regarding nutrients sensing, signaling and uptake is constantly increasing, however, we are still lacking the exact mechanism behind this complicated process. In this review, we have not only focused on how miRNAs play their dynamic roles to maintain an optimal supply of nutrients under stress situations, but also discussed some of the very important and commonly exhibited plant adaptations under distinct nutrients shortage. We have described in details that how miRNAs play their diverse roles to maintain distinct nutrients including $\mathrm{N}, \mathrm{P}, \mathrm{K}, \mathrm{S}$ and other mineral elements, however, it was difficult to clarify about how the miRNAs are involved in $\mathrm{K}$ metabolism, unfortunately the literature is still scarce to understand the precise molecular basis of miRNA/K interaction in plants. Nonetheless, plants successfully displayed certain strategies to effectively cope various nutrient stresses. For instance, most plants have reprogrammed their signaling network in the presence of miRNAs in order to trigger root architecture modifications under various nutrient stresses, consequently, optimizing nutrients availability to plants for their normal growth. Further, miRNAs-based modulation of specific transporters, was also a common strategy adapted by plants under nutrient stress in most cases. However, spatio-temporal regulation of miRNAs is essential for precise and systematic control of nutrient homeostasis. Moreover, the pseudo interaction between IPSI and miR399, represents unique insights into regulatory functions determined by its natural target mimicry, hence, identification of new endogenous target mimics will help us design more appropriate
miRNAs-oriented strategies to cope nutrient stress responses in plants.

Furthermore, long distance nutrients mobilization is characterized by phloem mediated communication, which was shown to be strongly associated with phloem specific miRNAs. Moreover, a tightly coordinated mechanism between miRNAs and various hormones has been observed, which is essential for wide scale dynamic regulation to efficiently control nutrients homeostasis across different cells/tissues within plant. However, we still do not know, how exactly plants sense external or internal nutrients scarcity initially to specifically respond to a peculiar nutrient element. We are also lacking sufficient evidences determining the correct upstream switches involved in this process. Other future challenges include, how the spatio-temporal regulation of nutrient homeostasis can be associated with physiological changes and what are the trade-offs between them during this course. Also, there is still limited knowledge about sensing and signaling responses associated with nutrient shortage, where nutrient elements itself serve as signaling molecules and interact with other stress related signals specifically phytohormones. Importantly, it is necessary to shatter the barriers and to know precise mechanisms involved in nutrients sensing, signaling, morpho-physiolological plant responses and miRNA based networking cascade to achieve our larger goals of reducing food insecurity.

\section{Acknowledgments}

The authors specially thank Prof. Pablo A. Manavella from Instituto de Agrobiotecnología del Litoral (IAL, Argentina) for benevolently providing the original content from his previous work. The authors acknowledge and thank the generous support provided from National Key Laboratory of Crop Genetic Improvement and National Center of Plant Gene Research, Huazhong Agricultural University, Wuhan 430070 China, in the event of writing this review.

\section{Competing financial interests}

The authors declare no competing financial interests.

\section{References}

Abadía J, Vázquez S, Rellán-Álvarez R, El-Jendoubi $H$, Abadía A, Álvarez-Fernández A, LópezMillán AF (2011) Towards a knowledge-based correction of iron chlorosis. Plant Physiol Biochem. 49: 471-482.

Abdel-Ghany SE, Pilon M (2008) MicroRNA-mediated systemic downregulation of copper protein expression in response to low copper availability in Arabidopsis. J Biol Chem. 283: 15932-15945.

Achkar NP, Cambiagno DA, Manavella PA (2016) miRNA Biogenesis: A Dynamic Pathway. Trends Plant Sci. 21: 1034-1044.

Adams E, Shin R (2014) Transport, signaling, and homeostasis of potassium and sodium in plants. J Integr Plant Biol. 56: 231-249.

Allen E, Xie Z, Gustafson AM, Carrington JC (2005) MicroRNA directed phasing during trans-acting siRNA biogenesis in plants. Cell. 121: 207-221. 
Andres-Colas N, Perea-Garcia A, Puig S, Peñarrubia L (2010) Deregulated copper transport affects Arabidopsis development especially in the absence of environmental cycles. Plant Physiol. 153: 170-184.

Anjum NA, Gill R, Kaushik M, Hasanuzzaman M, Pereira E, Ahmad I, Tuteja N, Gill SS (2015) ATP-sulfurylase, sulfur-compounds and plant stress tolerance. Front Plant Sci. 6: 210.

Ariel F, Brault-Hernandez M, Laffont C, Huault E, Brault M, Plet J, Moison M, Blanchet S, Ichante JL, Chabaud M, Carrere S, Crespi M, Chan RL, Frugier F (2012) Two direct targets of cytokinin signaling regulate symbiotic nodulation in Medicago truncatula. Plant Cell. 24: 3838-3852.

Aung K, Lin SI, Wu CC, Huang YT, Su CL, Chiou TJ (2006) pho2, a phosphate overaccumulator, is caused by a nonsense mutation in a microRNA399 target gene. Plant Physiol. 141: 1000-1011.

Babu N, Jyothi MN, Shivaram U, Narayanaswamy S, Rai DV, Devaraj VR (2014) Identification of miRNAs from French bean (Phaseolus vulgaris) under low nitrate stress. Turk J Biochem. 39: 1-8.

Baek D, Kim MC, Chun HJ, Kang S, Park HC, Shin G, Park J, Shen $\mathrm{M}$, Hong $\mathrm{H}$, Kim WY, Kim DH, Lee SY, Bressan RA, Bohnert HJ, Yun DJ (2013) Regulation of miR399f transcription by AtMYB2 affects phosphate starvation responses in Arabidopsis. Plant Physiol. 161: 362-373.

Barberon M, Zelazny E, Robert S, Conejero G, Curie C, Friml J, Vert G (2011) Monoubiquitin-dependent endocytosis of the IRON-REGULATED TRANSPORTER 1 (IRT1) transporter controls iron uptake in plants. Proc Natl Acad Sci USA. 108: E450-E458.

Barbier-Brygoo H, De Angeli A, Filleur S, Frachisse JM, Gambale F, Thomine S, Wege S (2011) Anion channels/transporters in plants: from molecular bases to regulatory networks. Annu Rev Plant Biol. 62: 25-51.

Barciszewska-Pacak M, Milanowska K, Knop K, Bielewicz D, Nuc P, Plewka P, Pacak AM, Vazquez F, Karlowski W, Jarmolowski A, Szweykowska-Kulinska Z (2015) Arabidopsis microRNA expression regulation in a wide range of abiotic stress responses. Front Plant Sci. 6: 410.

Bari R, Pant BD, Stitt M, Scheible WR (2006) PHO2, microRNA399, and PHR1 define a phosphate-signaling pathway in plants. Plant Physiol. 141: 988-999.

Barros-Carvalho GA, Paschoal AR, Marcelino-Guimaraes FC, Hungria M (2014) Prediction of potential novel microRNAs in soybean when in symbiosis. Genet Mol Res. 13: 8519-8529.

Bazin J, Khan GA, Combier JP, Bustos-Sanmamed P, Debernardi JM, Rodriguez R, Sorin C, Palatnik J, Hartmann C, Crespi M, Lelandais-Briere C (2013) miR396 affects mycorrhization and root meristem activity in the legume Medicago truncatula. Plant J. 74: 920-934.

Beauclair L, Yu A, Bouche N (2010) microRNA directed cleavage and translational repression of the copper chaperone for superoxide dismutase mRNA in Arabidopsis. Plant J. 62: 454-462.

Becker A, Theißen G (2003) The major clades of MADS-box genes and their role in the development and evolution of flowering plants. Mol Phylogenet Evol. 29: 464-489.

Benková E, Hejátko J (2009) Hormone interactions at the root apical meristem. Plant Mol Biol. 69: 383-396.
Bose J, Shabala L, Pottosin I, Zeng F, Velarde-Buendia AM, Massart A, Poschenrieder C, Hariadi Y, Shabala S (2014) Kinetics of xylem loading, membrane potential maintenance, and sensitivity of $\mathrm{K}^{+}$-permeable channels to reactive oxygen species: physiological traits that differentiate salinity tolerance between pea and barley. Plant Cell Environ. 37: 589-600.

Boualem A, Laporte P, Jovanovic M, Laffont C, Plet J, Combier JP, Niebel A, Crespi M, Frugier F (2008) MicroRNA166 controls root and nodule development in Medicago truncatula. Plant J. 54: 876-887.

Boursiac Y, Leran S, Corratge-Faillie C, Gojon A, Krouk G, Lacombe B (2013) ABA transport and transporters. Trends Plant Sci. 18: 325-333.

Buhtz A, Pieritz J, Springer F, Kehr J (2010) Phloem small RNAs, nutrient stress responses, and systemic mobility. BMC Plant Biol. 10: 1-13.

Bustos R, Castrillo G, Linhares F, Puga MI, Rubio V, Pérez-Pérez J, Solano R, Leyva A, PazAres J (2010) A central regulatory system largely controls transcriptional activation and repression responses to phosphate starvation in Arabidopsis. PLoS Genet. 6: e1001102.

Byrne SL, Foito A, Hedley PE, Morris JA, Stewart D, Barth S (2011) Early response mechanisms of perennial ryegrass (Lolium perenne) to phosphorus deficiency. Ann Bot. 107: 243-254.

Caballero F, Botella MA, Rubio L, Fernandez JA, Martinez V, Rubio F (2012) A Ca ${ }^{2+}$-sensitive system mediates low-affinity $\mathrm{K}^{+}$uptake in the absence of AKT1 in Arabidopsis plants. Plant Cell Physiol. 53: 2047-2059.

Canfield DE, Glazer AN, Falkowski PG (2010) The evolution and future of earth's nitrogen cycle. Science. 330: 192-196.

Carlsbecker A, Lee JY, Roberts CJ, Dettmer J, Lehesranta S, Zhou J, Lindgren O, Moreno-Risueno, MA, Vaten A, Thitamadee S, Campilho A, Sebastian J, Bowman JL, Helariutta Y, Benfey PN (2010) Cell signalling by microRNA165/6 directs gene dose-dependent root cell fate. Nature. 465: 316-321.

Chen X (2005) MicroRNA biogenesis and function in plants. FEBS Lett. 579: 5923-5931.

Chen M, Bao H, Wu QM, Wang YW (2015) Transcriptome-Wide Identification of miRNA targets under nitrogen deficiency in Populus tomentosa using degradome sequencing. Int J Mol Sci. 16: 13937-13958.

Chen M, Wei M, Dong ZH, Bao H, Wang YW (2016) Genomic identification of microRNA promoters and their cis-acting elements in Populus. Genes Genom. 38: 377-387.

Cherel I, Lefoulon C, Boeglin M, Sentenac H (2014) Molecular mechanisms involved in plant adaptation to low $\mathrm{K}(+)$ availability. J Exp Bot. 65: 833-848.

Chiou TJ, Aung K, Lin SI, Wu CC, Chiang SF, Su CL (2006) Regulation of phosphate homeostasis by microRNA in Arabidopsis. Plant Cell. 18: 412-421.

Chiou TJ, Lin SI (2011) Signaling network in sensing phosphate availability in plants. Annu Rev Plant Biol. 62: 185-206.

Crawford NM, Forde BG (2002) Molecular and developmental biology of inorganic nitrogen nutrition. In: The arabidopsis book; E Meyerowitz and C Somerville (eds). Rockville, MD: American Society of Plant Biologists (http://www.aspb.org/publications/arabidopsis). 
Cuperus JT, Fahlgren N, Carrington JC (2011) Evolution and functional diversification of MIRNA genes. Plant Cell. 23: 431-442.

Daras G, Rigas S, Tsitsekian D, lacovides TA, Hatzopoulos P (2015) Potassium transporter TRH1 subunits assemble regulating root-hair elongation autonomously from the cell fate determination pathway. Plant Sci. 231: 131-137.

Devers EA, Branscheid A, May P, Krajinski F (2011) Stars and symbiosis: microRNA- and microRNA*-mediated transcript cleavage involved in arbuscular mycorrhizal symbiosis. Plant Physiol. 156: 1990-2010.

De Luis A, Markmann K, Cognat V, Holt DB, Charpentier M, Parniske M, Stougaard J, Voinnet O (2012) Two microRNAs linked to nodule infection and nitrogen-fixing ability in the legume Lotus japonicus. Plant Physiol. 160: 2137-2154.

Engstrom EM, Andersen CM, Gumulak-Smith J, Hu J, Orlova E, Sozzani R, Bowman JL (2011) Arabidopsis homologs of the petunia hairy meristem gene are required for maintenance of shoot and root indeterminacy. Plant Physiol. 155: 735-750.

Fischer JJ, Beatty PH, Good AG, Muench DG (2013) Manipulation of microRNA expression to improve nitrogen use efficiency. Plant Sci. 210: 70-81.

Franco-Zorrilla JM, Valli A, Todesco M, Mateos I, Puga MI, RubioSomoza I, Leyva A, Weigel D, Garcia JA, PazAres J (2007) Target mimicry provides a new mechanism for regulation of microRNA activity. Nat Genet. 39: 1033-1037.

Fuchs I, Stolzle S, Ivashikina N, Hedrich R (2005) Rice $\mathrm{K}^{+}$ uptake channel OsAKT1 is sensitive to salt stress. Planta. 221: 212-221.

Fujii H, Chiou TJ, Lin SI, Aung K, Zhu JK (2005) A miRNA involved in phosphate-starvation response in Arabidopsis. Curr Biol. 15: 2038-2042.

Garnett T, Plett D, Heuer S, Okamoto M (2015) Genetic approaches to enhancing nitrogen-use efficiency (NUE) in cereals: challenges and future directions. Funct Plant Biol. 42: 921-941.

Gao N, Su Y, Min J, Shen W, Shi W (2010) Transgenic tomato overexpressing ath-miR399d has enhanced phosphorus accumulation through increased acid phosphatase and proton secretion as well as phosphate transporters. Plant Soil. 334: 123-136.

Gao S, Yang L, Zeng HQ, Zhou ZS, Yang ZM, Li H, Sun D, Xie FL, Zhang BH (2016) A cotton miRNA is involved in regulation of plant response to salt stress. Sci Rep. 6: e19736.

Gifford ML, Dean A, Gutierrez RA, Coruzzi GM, Birnbaum KD (2008) Cell-specific nitrogen responses mediate developmental plasticity. Proc Natl Acad Sci USA. 105: 803-808.

Gill SS, Anjum NA, Hasanuzzaman M, Gill R, Trivedi DK, Ahmad I, Pereira E, Tuteja N (2013) Glutathione and glutathione reductase: a boon in disguise for plant abiotic stress defense operations. Plant Physiol Biochem. 70: 204-212.

Glass ADM, Siddiqi MY (1995) Nitrogen absorption in higher plants. In: Nitrogen nutrition in higher plants; Srivastava HS, Singh RP (eds). pp 21-56. Associated Publishing, New Delhi.

Griffiths-Jones S, Grocock RJ, Van Dongen S, Bateman A, Enright AJ (2006) miRBase: microRNA sequences, targets and gene nomenclature. Nucleic Acids Res. 34: D140-D144.
Gu M, Xu K, Chen A, Zhu Y, Tang G, Xu G (2010) Expression analysis suggests potential roles of microRNAs for phosphate and arbuscular mycorrhizal signaling in Solanum lycopersicum. Physiol Plantarum. 138: 226-237.

Guo SY, Xu YY, Liu HH, Mao ZW, Zhang C, Ma Y, Zhang QR, Meng Z, Chong K (2013) The interaction between OsMADS57 and OsTB1 modulates rice tillering via DWARF14. Nat Commun. 4: 1566.

Gutierrez L, Mongelard G, Flokova K, Pacurar DI, Novak O, Staswick P, Kowalczyk M, Pacurar M, Demailly H, Geiss G, Bellini C (2012) Auxin controls Arabidopsis adventitious root initiation by regulating jasmonic acid homeostasis. Plant Cell. 24: 2515-2527.

Hackenberg M, Huang PJ, Huang CY, Shi BJ, Gustafson P, Langridge $P$ (2013) A comprehensive expression profile of microRNAs and other classes of non-coding small RNAs in barley under phosphorous-deficient and -sufficient conditions. DNA Res. 20: 109-125.

Hajiboland R, Farhanghi F, Aliasgharpour M (2012) Morphological and anatomical modifications in leaf, stem and roots of four plant species under boron deficiency conditions. An Biol. 34: 15-29.

Hänsch R, Mendel RR (2009) Physiological functions of mineral micronutrients $(\mathrm{Cu}, \mathrm{Zn}, \mathrm{Mn}, \mathrm{Fe}, \mathrm{Ni}, \mathrm{Mo}, \mathrm{B}, \mathrm{Cl})$. Curr Opin Plant Biol. 12: 259-266.

Hsieh LC, Lin SI, Shih ACC, Chen JW, Lin WY, Tseng CY, Li WH, Chiou TJ (2009) Uncovering small RNA-mediated responses to phosphate deficiency in Arabidopsis by deep sequencing. Plant Physiol. 151: 2120-2132.

Huang SQ, Xiang AL, Che LL, Chen S, Li H, Song JB, Yang ZM (2010) A set of miRNAs from Brassica napus in response to sulphate deficiency and cadmium stress. Plant Biotechnol J. 8: 887-899.

Huang TK, Han CL, Lin SI, Chen YJ, Tsai YC, Chen YR, Chen JW, Lin WY, Chen PM, Liu TY, Chen YS, Sun CM, Chiou TJ (2013) Identification of downstream components of ubiquitin-conjugating enzyme PHOSPHATE2 by quantitative membrane proteomics in Arabidopsis roots. Plant Cell. 25: 4044-4060.

Huang J, Li Z, Zhao D (2016) Deregulation of the OsmiR160 target gene OsARF18 causes growth and developmental defects with an alteration of auxin signaling in rice. Sci Rep. 6: e29938.

Hu B, Wang W, Deng K, Li H, Zhang Z, Chu C (2015) MicroRNA399 is involved in multiple nutrient starvation responses in rice. Front Plant Sci. 6: 188.

Iglesias MJ, Terrile MC, Windels D, Lombardo MC, Bartoli CG, Vazquez F, Estelle M, Casalongue CA (2014) MiR393 regulation of auxin signaling and redox-related components during acclimation to salinity in Arabidopsis. PLoS One. 9: e107678.

Jian H, Wang J, Wang T, Wei L, Li J, Liu L (2016) Identification of rapeseed microRNAs involved in early stage seed germination under salt and drought stresses. Front Plant Sci. 7: 658 .

Jobbagy EG, Jackson RB (2001) The distribution of soil nutrients with depth: global patterns and the imprint of plants. Biogeochemistry. 53: 51-77.

Joshi T, Yan Z, Libault M, Jeong DH, Park S, Green PJ, Sherrier DJ, Farmer A, May G, Meyers BC, Xu D, Stacey G (2010) Prediction of novel miRNAs and associated target genes in Glycine max. BMC Bioinformatics. 11(Suppl 1): S14. 
Jung IL, Ryu M, Cho SK, Shah P, Lee JH, Bae H, Kim IG, Yang SW (2015) Cesium Toxicity Alters MicroRNA Processing and AGO1 Expressions in Arabidopsis thaliana. PLoS One. 10: e0125514.

Kant S, Peng M, Rothstein SJ (2011) Genetic regulation by NLA and microRNA827 for maintaining nitrate-dependent phosphate homeostasis in Arabidopsis. PLoS Genet. 7: e1002021.

Kataoka T, Watanabe-Takahashi A, Hayashi N, Ohnishi M, Mimura T, Buchner P, Hawkesford MJ, Yamaya T, Takahashi H (2004) Vacuolar sulfate transporters are essential determinants controlling internal distribution of sulfate in Arabidopsis. Plant Cell. 16: 2693-2704.

Kawashima CG, Yoshimoto N, Maruyama-Nakashita A, Tsuchiya YN, Saito K, Takahashi H, Dalmay T (2009) Sulphur starvation induces the expression of microRNA-395 and one of its target genes but in different cell types. Plant J. 57: 313-321.

Kawashima CG, Matthewman CA, Huang $S$, Lee BR, Yoshimoto N, Koprivova A, Rubio-Somoza I, Todesco M, Rathjen T, Saito K, Takahashi H, Dalmay T, Kopriva S (2011) Interplay of SLIM1 and miR395 in the regulation of sulfate assimilation in Arabidopsis. Plant J. 66: 863-876.

Kehr J, 2013. Systemic regulation of mineral homeostasis by micro RNAs. Front Plant Sci. 4: 145.

Kim VN (2005) MicroRNA biogenesis: coordinated cropping and dicing. Nat Rev Mol Cell Biol. 6: 376-385.

Kim YJ, Zheng B, Yu Y, Won SY, Mo B, Chen X (2011) The role of mediator in small and long noncoding RNA production in Arabidopsis thaliana. EMBO J. 30: 814-822.

Kim MJ, Ruzicka D, Shin R, Schachtman DP (2012) The Arabidopsis AP2/ERF transcription factor RAP2.11 modulates plant response to low-potassium conditions. Mol Plant. 5: 1042-1057.

Kirkby EA, Johnston AE (2008) Soil and fertilizer phosphorusin relation to crop nutrition. In: The ecophysiology of plant-phosphorus interactions; Hammond JP, White PJ (eds). pp 177-223. Springer, Dordrecht.

Kong WW, Yang ZM (2010) Identification of iron-deficiency responsive microRNA genes and cis-elements in Arabidopsis. Plant Physiol Biochem. 48: 153-159.

Krapp A, Berthome R, Orsel M, Mercey-Boutet S, Yu A, Castaings L, Elftieh S, Major H, Renou JP, Daniel-Vedele F (2011) Arabidopsis roots and shoots show distinct temporal adaptation patterns toward nitrogen starvation. Plant Physiol. 157: 1255-1282.

Krapp A, David LC, Chardin C, Girin T, Marmagne A, Leprince A-S, Chaillou S, Ferrario-Méry S, Meyer C, Daniel-Vedele F (2014) Nitrate transport and signaling in Arabidopsis. J Exp Bot. 65: 789-798.

Krouk G, Ruffel S, Gutiérrez RA, Gojon A, Crawford NM, Coruzzi GM, Lacombe B (2011) A framework integrating plant growth with hormones and nutrients. Trends Plant Sci. 16: 178-182.

Kuo HF, Chiou TJ (2011) The role of microRNAs in phosphorus deficiency signaling. Plant Physiol. 156: 1016-1024.

Lanet E, Delannoy E, Sormani R, Floris M, Brodersen P, Crete P, Voinnet O, Robaglia C (2009) Biochemical evidence for translational repression by Arabidopsis microRNAs. Plant Cell. 21: 1762-1768.
Lavenus J, Goh T, Roberts I, Guyomarch S, Lucas M, De Smet I, Fukaki H, Beeckman T, Bennett M, Laplaze L (2013) Lateral root development in Arabidopsis: fifty shades of auxin. Trends Plant Sci. 18(8), 450-458.

Lebaudy A, Very AA, Sentenac $\mathrm{H}(2007) \mathrm{K}^{+}$channel activity in plants: genes, regulations and functions. FEBS Lett. 581: 2357-2366.

Lelandais-Briere C, Naya L, Sallet E, Calenge F, Frugier F, Hartmann C, Gouzy J, Crespi M (2009) Genome-wide Medicago truncatula small RNA analysis revealed novel microRNAs and isoforms differentially regulated in roots and nodules. Plant Cell. 21: 2780-2796.

Léran S, Varala K, Boyer JC, Chiurazzi M, Crawford N, Daniel-Vedele F, David L, Dickstein R, Fernandez E, Forde B, Gassmann W, Geiger D, Gojon A, Gong JM, Halkier BA, Harris JM, Hedrich R, Limami AM, Rentsch D, Seo M, Tsay YF, Zhang MY, Coruzzi G, Lacombe B (2014) A unified nomenclature of NITRATE TRANSPORTER 1/PEPTIDE TRANSPORTER family members in plants. Trends Plant Sci. 19: 5-9.

Lezhneva L, Kiba $T$, Feria-Bourrellier $A B$, Lafouge $F$, Boutet-Mercey S, Zoufan P, Sakakibara H, Daniel-Vedele F, Krapp A (2014) The Arabidopsis nitrate transporter NRT2.5 plays a role in nitrate acquisition and remobilization in nitrogen-starved plants. Plant J. 80: 230-241.

Liang G, Yang F, Yu D (2010) MicroRNA395 mediates regulation of sulfate accumulation and allocation in Arabidopsis thaliana. Plant J. 62: 1046-1057.

Liang G, He H, Yu D (2012) Identification of nitrogen starvation-responsive microRNAs in Arabidopsis thaliana. PLoS One. 7: e48951.

Liang G, Li Y, He H, Wang F, Yu D (2013) Identification of miRNAs and miRNA-mediated regulatory pathways in Carica papaya. Planta. 238: 739-752.

Liang C, Wang J, Zhao J, Tian J, Liao H (2014) Control of phosphate homeostasis through gene regulation in crops. Curr Opin Plant Biol. 21: 59-66.

Liang G, Ai Q, Yu D (2015) Uncovering miRNAs involved in crosstalk between nutrient deficiencies in Arabidopsis. Sci Rep. 5: e11813.

Li H, Deng Y Wu T, Subramanian S, Yu O (2010) Misexpression of miR482, miR1512, and miR1515 increases soybean nodulation. Plant Physiol. 153: 1759-1770.

Li J, Guo GH, Guo WW, Guo GG, Tong D, Ni ZF, Sun QX, Yao YY (2012) miRNA164-directed cleavage of ZmNAC1 confers lateral root development in maize (Zea mays L.). BMC Plant Biol. 12: 220.

Li YL, Zhang Y, Shi DQ, Liu XJ, Qin J, Ge Q, Xu LH, Pan XL, Li W, Zhu YY, Xu J (2013) Spatial-temporal analysis of zinc homeostasis reveals the response mechanisms to acute zinc deficiency in Sorghum bicolor. New Phytol. 200: $1102-1115$.

Li C and Zhang B (2016) MicroRNAs in control of plant development. J Cell Physiol. 231: 303-313.

Li H, Hu B, Wang W, Zhang ZH, Liang Y, Gao XK, Li P, Liu YQ, Zhang LH, Chu CC (2016) Identification of microRNAs in rice root in response to nitrate and ammonium. J Genet Genomics. 43: 651-661.

Lin SI, Chiang SF, Lin WY, Chen JW, Tseng CY, Wu PC, Chiou TJ (2008) Regulatory network of microRNA399 and PHO2 by systemic signaling. Plant Physiol. 147: 732-746. 
Lin SI, Santi C, Jobet E, Lacut E, Kholti NE, Karlowski WM, Verdeil JL, Breitler JC, Perin C, Ko SS, Guiderdoni E, Chiou TJ, Echeverria M (2010) Complex regulation of two target genes encoding SPX-MFS proteins by rice miR827 in response to phosphate starvation. Plant Cell Physiol. 51: 2119-2131.

Liu Q, Zhang YC, Wang CY, Luo YC, Huang QJ, Chen SY, Zhou $H$, Qu LH, Chen YQ (2009) Expression analysis of phytohormone-regulated microRNAs in rice, implying their regulation roles in plant hormone signaling. FEBS Lett. 583: 723-728.

Liu TY, Huang TK, Tseng CY, Lai YS, Lin SI, Lin WY, Chen JW, Chiou TJ (2012) PHO2-dependent degradation of PHO1 modulates phosphate homeostasis in Arabidopsis. Plant Cell. 24: 2168-2183.

Liu Z, Li J, Wang L, Li Q, Lu Q, Yu Y, Li S, Bai MY, Hu Y, Xiang F (2016) Repression of callus initiation by the miRNA-directed interaction of auxin-cytokinin in Arabidopsis thaliana. Plant J. 87: 391-402.

Liu KH, Niu Y, Konishi M, Wu Y, Du H, Sun Chung $H$, Li L, Boudsocq M, McCormack M, Maekawa S, Ishida T, Zhang C, Shokat K, Yanagisawa S, Sheen J (2017) Discovery of nitrate-CPK-NLP signalling in central nutrient-growth networks. Nature. 545: 311-316.

Lundmark M, Korner CJ, Nielsen TH (2010) Global analysis of microRNA in Arabidopsisin response to phosphate starvation as studied by locked nucleic acid-based microarrays. Physiol Plantarum. 140: 57-68.

Lu YB, Yang LT, Qi YP, Li Y, Li Z, Chen, YB, Huang ZR, Chen LS (2014) Identification of boron-deficiency-responsive microRNAs in Citrus sinensis roots by Illumina sequencing. BMC Plant Biol. 14: 123.

Lu YB, Qi YP, Yang LT, Guo P, Li Y, Chen LS (2015) Boron-deficiency-responsive microRNAs and

their targets in Citrus sinensis leaves. BMC Plant Biol. 15: 271.

Madsen LH, Tirichine L, Jurkiewicz A, Sullivan JT, Heckmann AB, Bek AS, Ronson CW, James EK, Stougaard J (2010) The molecular network governing nodule organogenesis and infection in the model legume Lotus japonicus. Nat Commun. 1: 10.

Mansoorkhani FM, Seymour GB, Swarup R, Bagheri HM, Ramsey RJL, Thompson AJ (2014) Environmental, developmental, and genetic factors controlling root system architecture. Biotechnol Genet Eng Rev. 30: 95-112.

Marin E, Jouannet V, Herz A, Lokerse AS, Weijers D, Vaucheret H, Nussaume L, Crespi MD, Maizel A (2010) MiR390, Arabidopsis TAS3 tasiRNAs, and their AUXIN RESPONSE FACTOR targets define an autoregulatory network quantitatively regulating lateral root growth. Plant Cell. 22: 1104-1117.

Marschner H (1995) Functions of Mineral Nutrients: Macronutrients. In: Mineral nutrition of higher plants (second edition); Marschner H (ed). Academic Press, London. pp 229-312.

Marschner P (2011) Marschner's Mineral Nutrition of Higher Plants, Third edition. Academic Press, London. 672 pp.

Martínez-Cordero MA, Martínez V, Rubio F (2004) Cloning and functional characterization of the high-affinity $\mathrm{K}^{+}$ transporter HAK1 of pepper. Plant Mol Biol. 56: 413-421.

Matts J, Jagadeeswaran G, Roe BA, Sunkar R (2010) Identification of microRNAs and their targets in switchgrass, a model biofuel plant species. J Plant Physiol. 167: 896-904.

Mattiello EM, Ruiz HA, Neves JC, Ventrella MC, Araujo WL (2015) Zinc deficiency affects physiological and anatomical characteristics in maize leaves. J Plant Physiol. 183: 138-143.

Matthewman CA, Kawashima CG, Huska D, Csorba T, Dalmay T, Kopriva S (2012) miR395 is a

general component of the sulfate assimilation regulatory network in Arabidopsis. FEBS Lett. 586: 3242-3248.

Meng Y, Chen D, Ma X, Mao C, Cao J, Wu P, Chen M (2010) Mechanisms of microRNA-mediated auxin signaling inferred from the rice mutant osaxr. Plant Signal Behav. 5: 252-254.

Miller AJ, Fan XR, Orsel M Smith SJ, Wells DM (2007) Nitrate transport and signalling. J Exp Bot. 58: 2297-2306.

Mlodzinska E and Zboinska M (2016) Phosphate uptake and allocation-a closer look at Arabidopsis thaliana L. and Oryza sativa L. Front Plant Sci. 7: 1198.

Muthayya S, Sugimoto JD, Montgomery S, Maberly GF (2014) An overview of global rice production, supply, trade, and consumption. Ann NY Acad Sci. 1324: 7-14.

Negi J, Matsuda O, Nagasawa T, Oba Y, Takahashi H, Kawai-Yamada M,Uchimiya H, Hashimoto M, Iba K (2008) $\mathrm{CO}_{2}$ regulator SLAC1 and its homologues are essential for anion homeostasis in plant cells. Nature. 452: 483-486.

Nischal L, Mohsin M, Khan I, Kardam H, Wadhwa A, Abrol YP, Iqbal M, Ahmad A (2012) Identification and comparative analysis of microRNAs associated with low- $\mathrm{N}$ tolerance in rice genotypes. PLoS One. 7: e50261.

Nieves-Cordones M, Alemán F, Martínez V, Rubio F (2014) K ${ }^{+}$ uptake in plant roots. the systems involved, their regulation and parallels in other organisms. J Plant Physiol. 171: 688-695.

Nieves-Cordones $M$, Martinez-Cordero MA, Martinez $V$, Rubio $F$ (2007) $\mathrm{An} \mathrm{NH}_{4}{ }^{+}$-sensitive component dominates high-affinity $\mathrm{K}^{+}$uptake in tomato plants. Plant Sci. 172: 273-280.

Nizampatnam NR, Schreier SJ, Damodaran S, Adhikari S, Subramanian S (2015) microRNA160 dictates stage-specific auxin and cytokinin sensitivities and directs soybean nodule development. Plant J. 84: 140-153.

Noguero M and Lacombe B (2016) Transporters Involved in Root Nitrate Uptake and Sensing by Arabidopsis. Front Plant Sci. 7: 1391.

Nussaume L, Kanno S, Javot H, Marin E, Pochon N, Ayadi A, Nakanishi TM, Thibaud MC (2011) Phosphate import in plants: focus on the PHT1 transporters. Front Plant Sci. 2: 83.

Oosterhuis DM, Loka DA, Raper TB (2013) Potassium and stress alleviation: physiological functions and management of cotton. J Plant Nutr Soil Sc. 176: 331-343.

Ozhuner E, Eldem V, Ipek A, Okay S, Sakcali S, Zhang B, Boke $\mathrm{H}$, Unver T (2013) Boron stress responsive microRNAs and their targets in barley. PLoS One. 8: e59543.

Pant BD, Buhtz A, Kehr J, Scheible WR (2008) MicroRNA399 is a long-distance signal for the regulation of plant phosphate homeostasis. Plant J. 53: 731-738.

Pant BD, Musialak-Lange M, Nuc P, May P, Buhtz A, Kehr J, Walther D, Scheible WR (2009) Identification of nutrient-responsive Arabidopsis and rapeseed microRNAs by comprehensive real-time polymerase chain reaction 
profiling and small RNA sequencing. Plant Physiol. 150: 1541-1555.

Pang J, Milroy SP, Rebetzke GJ, Palta JA (2015) The influence of shoot and root size on nitrogen uptake in wheat is affected by nitrate affinity in the roots during early growth. Funct Plant Biol. 42: 1179-1189.

Pei L, Jin Z, Li K, Yin H, Wang J, Yang A (2013) Identification and comparative analysis of low phosphate tolerance associated microRNAs in two maize genotypes. Plant Physiol Biochem. 70: 221-234.

Peng M, Hannam C, Gu H, Bi YM, Rothstein SJ (2007) A mutation in NLA, which encodes a RING-type ubiquitin ligase, disrupts the adaptability of Arabidopsis to nitrogen limitation. Plant J. 50: 320-337.

Perilli S, Di Mambro R, Sabatini S (2012) Growth and development of the root apical meristem. Curr Opin Plant Biol. 15: 17-23.

Petricka JJ, Winter CM, Benfey PN (2012) Control of Arabidopsis root development. Annu Rev Plant Biol. 63: 563-590.

Phillips JR, Dalmay T, Bartels D (2007) The role of small RNAs in abiotic stress. FEBS Lett. 581: 3592-3597.

Pilon M (2016) The copper microRNAs. New Phytol. 213: 1030-1035.

Ren Y, Sun F, Hou J, Chen L, Zhang Y, Kang X, Wang Y (2015) Differential profiling analysis of miRNAs reveals a regulatory role in low $\mathrm{N}$ stress response of Populus. Funct Integr Genomics. 15: 93-105.

Rodriguez RE, Schommer C, Palatnik JF (2016) Control of cell proliferation by microRNAs in plants. Curr Opin Plant Biol. 34: 68-76.

Rubio V, Bustos R, Irigoyen ML, Cardona-Lopez X, Rojas-Triana M, PazAres J (2009) Plant hormones and nutrient signaling. Plant Mol Biol. 69: 361-373.

Schmidt SB, Jensen PE, Husted S (2016) Manganese deficiency in plants: the impact on photosystem II. Trends Plant Sci. 21: 622-632.

Shi DQ, Zhang Y, Li YL, Xu J (2013) Identification of zinc deficiency-responsive microRNAs in Brassica juncea roots by small RNA sequencing. J Integr Agr. 12: 2036-2044.

Shin R, Berg RH, Schachtman DP (2005) Reactive oxygen species and root hairs in Arabidopsis root response to nitrogen, phosphorus and potassium deficiency. Plant Cell Physiol. 46: 1350-1357.

Shin LJ and Yeh KC (2012) Overexpression of Arabidopsis ATX1 retards plant growth under severe copper deficiency. Plant Signal Behav. 7: 1082-1083.

Shu L and Hu Z (2012) Characterization and differential expression of microRNAs elicited by sulfur deprivation in Chlamydomonas reinhardtii. BMC Genomics. 13: 108.

Simon SA, Meyers BC, Sherrier DJ (2009) MicroRNAs in the Rhizobia Legume Symbiosis. Plant Physiol. 151: 1002-1008.

Sinha SK, Rani M, Bansal N, Gayatri Venkatesh K, Mandal PK (2015) Nitrate starvation induced changes in root system architecture, carbon:nitrogen metabolism, and miRNA expression in nitrogen-responsive wheat genotypes. Appl Biochem Biotech. 177: 1299-1312.

Socha AL, Guerinot ML (2014) Mn-euvering manganese: the role of transporter gene family members in manganese uptake and mobilization in plants. Front Plant Sci. 5: 106.

Song JB, Gao S, Sun D, Li H, Shu XX, Yang ZM (2013) miR394 and LCR are involved in Arabidopsis salt and drought stress responses in an abscisic acid-dependent manner. BMC Plant Biol. 13: 210.

Song AP, Wang LX, Chen SM, Jiang JF, Guan ZY, Li PL, Chen FD (2015) Identification of nitrogen starvation-responsive microRNAs in Chrysanthemum nankingense. Plant Physiol Biochem. 91: 41-48.

Song $L$ and Liu D (2015) Ethylene and plant responses to phosphate deficiency. Front Plant Sci. 6: 796.

Stepanova AN and Alonso JM, 2009. Ethylene signaling and response, where different regulatory modules meet. Curr Opin Plant Biol. 12: 548-555.

Straltsova D, Chykun P, Subramaniam S, Sosan A, Kolbanov D, Sokolik A, Demidchik V (2014) Cation channels are involved in brassinosteroid signalling in higher plants. Steroids. 97: 98-106.

Subramanian S, Fu Y, Sunkar R, Barbazuk WB, Zhu JK, Yu O (2008) Novel and nodulation-regulated microRNAs in soybean roots. BMC Genomics. 9: 160.

Sun SB, Gu M, Cao Y, Huang XP, Zhang X, Ai PH, Zhao JN, Fan $X R, X u$ GH (2012) A constitutive expressed phosphate transporter, OsPht1;1, modulates phosphate uptake and translocation in phosphate-replete rice. Plant Physiol. 159: 1571-1581.

Sunkar R, Kapoor A, Zhu JK (2006) Posttranscriptional induction of two $\mathrm{Cu} / \mathrm{Zn}$ superoxide dismutase genes in Arabidopsis is mediated by downregulation of miR398 and important for oxidative stress tolerance. Plant Cell. 18: 2051-2065.

Sunkar R, Chinnusamy V, Zhu J, Zhu JK (2007) Small RNAs as big players in plant abiotic stress responses and nutrient deprivation. Trends Plant Sci. 12: 301-319.

Sunkar R, Li YF, Jagadeeswaran G (2012) Functions of microRNAs in plant stress responses. Trends Plant Sci. 17: 196-203.

Swarup R, Perry P, Hagenbeek D, Van Der Straeten D, Beemster GT, Sandberg G, Bhalerao R, Ljung K, Bennett MJ (2007) Ethylene upregulates auxin biosynthesis in Arabidopsis seedlings to enhance inhibition of root cell elongation. Plant Cell. 19: 2186-2196.

Takahashi H (2010) Regulation of sulfate transport and assimilation in plants. Int Rev Cell Mol Biol. 281: 129-159.

Takehisa H, Sato Y, Antonio BA, Nagamura Y (2013) Global transcriptome profile of rice root in response to essential macronutrient deficiency. Plant Signal Behav. 8: e24409.

ten Hoopen F, Cuin TA, Pedas P, Hegelund JN, Shabala S, Schjoerring JK, Jahn TP (2010) Competition between uptake of ammonium and potassium in barley and Arabidopsis roots: molecular mechanisms and physiological consequences. J Exp Bot. 61: 2303-2315.

Trevisan S, Nonis A, Begheldo M, Manoli A, Palme K, Caporale G, Ruperti B, Quaggiotti S (2012a) Expression and tissue-specific localization of nitrate-responsive miRNAs in roots of maize seedlings. Plant Cell Environ. 35: 1137-1155.

Trevisan S, Begheldo M, Nonis A, Quaggiotti S (2012b) The miRNA-mediated post-transcriptional regulation of maize response to nitrate. Plant Signal Behav. 7: 822-826.

Turner M, Nizampatnam NR, Baron M, Coppin S, Damodaran S, Adhikari S, Arunachalam SP, Yu O, Subramanian S (2013) Ectopic expression of miR160 results in auxin hypersensitivity, cytokinin hyposensitivity, and inhibition of symbiotic nodule development in soybean. Plant Physiol. 162: 2042-2055. 
Valdes-Lopez O, Yang SS, Aparicio-Fabre R, Graham PH, Reyes JL, Vance CP, Hernandez G (2010) MicroRNA expression profile in common bean (Phaseolus vulgaris) under nutrient deficiency stresses and manganese toxicity. New Phytol. 187: 805-818.

Vidal EA, Araus V, Lu C, Parry G, Green PJ, Coruzzi GM, Gutierrez RA (2010) Nitrate-responsive miR393/AFB3 regulatory module controls root system architecture in Arabidopsis thaliana. Proc Natl Acad Sci USA. 107: 4477-4482.

Vidal EA, Moyano TC, Krouk G, Katari MS, Tanurdzic M, McCombie WR, Coruzzi GM, Gutierrez RA (2013) Integrated RNA-seq and sRNA-seq analysis identifies novel nitrate-responsive genes in Arabidopsis thaliana roots. BMC Genomics. 14: 701.

Wang JW, Wang L, Mao YB Cai WJ, Xue HW, Chen XY (2005) Control of root cap formation by microRNA-targeted auxin response factors in Arabidopsis. Plant Cell. 17: 2204-2216.

Wang YW, Li PC, Cao XF, Wang XJ, Zhang AM, Li X (2009) Identification and expression analysis of miRNAs from nitrogen-fixing soybean nodules. Biochem Biophys Res Commun. 378: 799-803.

Wang C, Huang W, Ying Y, Li S, Secco D, Tyerman S, Whelan J, Shou H (2012) Functional characterization of the rice SPX-MFS family reveals a key role of OsSPX-MFS1 in controlling phosphate homeostasis in leaves. New Phytol. 196: 139-148.

Wang Y, Wu WH (2013) Potassium transport and signaling in higher plants. Annu Rev Plant Biol. 64: 451-476.

Wang YJ, Zhang CJ, Hao QN, Sha AH, Zhou R, Zhou XA, Yuan LP (2013) Elucidation of miRNAs-mediated responses to low nitrogen stress by deep sequencing of two soybean genotypes. PLoS One. 8: e67423.

Wang Y, Wang L, Zou Y, Chen L, Cai Z, Zhang S, Zhao F, Tian Y, Jiang Q, Ferguson BJ, Gresshoff PM, Li X (2014) Soybean miR172c targets the repressive AP2 transcription factor NNC1 to activate ENOD40 expression and regulate nodule initiation. Plant Cell. 26: 4782-4801.

Wang B, Sun YF, Song N, Wei JP, Wang XJ, Feng H, Yin ZY, Kang ZS (2014) MicroRNAs involving in cold, wounding and salt stresses in Triticum aestivum L. Plant Physiol Biochem. 80: 90-96.

Wang JJ and Guo HS (2015) Cleavage of indole-3-acetic acid inducible28 mRNA by microRNA847 upregulates auxin signaling to modulate cell proliferation and lateral organ growth in Arabidopsis. Plant Cell. 27: 574-590.

Wang Y, Li K, Chen L Zou YM, Liu HP, Tian YP, Li DX, Wang R, Zhao F, Ferguson BJ, Gresshoff PM, Li X (2015) MicroRNA167-directed regulation of the auxin response factors GmARF8a and GmARF8b is required for soybean nodulation and lateral root development. Plant Physiol. 168: 984-999.

Waters BM, Mcinturf SA, Stein RJ (2012) Rosette iron deficiency transcript and microRNA profiling reveals links between copper and iron homeostasis in Arabidopsis thaliana. J Exp Bot. 63: 5903-5918.

Wege S, Khan GA, Jung JY, Vogiatzaki E, Pradervand S, Aller I, Meyer AJ, Poirier Y (2016) The EXS domain of PHO1 participates in the response of shoots to phosphate deficiency via a root-to-shoot signal. Plant Physiol. 170: 385-400.
Willmann MR and Poethig RS (2005) Time to grow up: the temporal role of smallRNAs in plants. Curr Opin Plant Biol. 8: 548-552.

Windels D, Bielewicz D, Ebneter $M$, Jarmolowski $A$, Szweykowska-Kulinska Z, Vazquez F (2014) miR393 is Required for Production of Proper Auxin Signalling Outputs. PLoS One. 9: e95972.

Wu L, Zhou H, Zhang Q, Zhang J, Ni F, Liu C, Qi Y (2010) DNA methylation mediated by a microRNA pathway. Molecular Cell. 38: 465-475.

Xu J, Li HD, Chen LQ, Wang Y, Liu LL He L, Wu WH (2006) A protein kinase, interacting with two calcineurin B-like proteins, regulates $\mathrm{K}^{+}$transporter AKT1 in Arabidopsis. Cell. 125: $1347-1360$.

Xu Z, Zhong S, Li X, Li W, Rothstein SJ, Zhang S, Bi Y, Xie C (2011) Genome-wide identification of microRNAs in response to low nitrate availability in maize leaves and roots. PLoS One. 6: e28009.

Xu F, Liu Q, Chen LY, Kuang JB, Walk T, Wang JX, Liao H (2013) Genome wide identification of soybean microRNAs and their targets reveals their organ specificity and responses to phosphate starvation. BMC Genomics. 14: 66.

Xu XB, Bai HQ, Liu CP, Chen EY, Chen QG, Zhuang JY, Shen B (2014) Genome-wide analysis of microRNAs and their target genes related to leaf senescence of rice. PLoS One. 9: e114313.

Yan Z, Hossain MS, Wang J, Valdes-Lopez O, Liang Y, Libault M, Qiu L, Stacey G (2013) miR172 regulates soybean nodulation. Mol Plant Microbe Interact. 26: 1371-1377.

Yan Y, Wang H, Hamera S, Chen X, Fang R (2014) miR444a has multiple functions in the rice nitrate-signaling pathway. Plant J. 78: 44-55.

Yang ZM and Chen J (2013) A potential role of microRNAs in plant response to metal toxicity. Metallomics. 5: 1184-1190.

Ye Y, Yuan J, Chang X, Yang M, Zhang L, Lu K, Lian XM (2015) The phosphate transporter gene OsPht1;4 is involved in phosphate homeostasis in rice. PLoS One. 10: e0126186.

Yoon EK, Yang JH, Lim J, Kim SH, Kim SK, Lee WS (2010) Auxin regulation of the microRNA390-dependent transacting small interfering RNA pathway in Arabidopsis lateral root development. Nucleic Acids Res. 38: 1382-1391.

Yoshimoto N, Inoue E, Watanabe-Takahashi A, Saito K, Takahashi H (2007) Posttranscriptional regulation of high-affinity sulfate transporters in Arabidopsis by sulfur nutrition. Plant Physiol. 145: 378-388.

Yuan H, Liu D (2008) Signaling components involved in plant responses to phosphate starvation. J Integr Plant Biol. 50: 849-859.

Zeng HQ, Zhu YY, Huang SQ, Yang ZM (2010) Analysis of phosphorus-deficient responsive miRNAs and cis-elements from soybean (Glycine max L.). J Plant Physiol. 167: 1289-1297.

Zeng QY, Yang CY, Ma QB, Li XP, Dong WW, Nian H (2012) Identification of wild soybean miRNAs and their target genes responsive to aluminum stress. BMC Plant Biol. 12: 182.

Zhang W, Gao S, Zhou X, Chellappan P, Chen Z, Zhou X, Zhang X, Fromuth N, Coutino G, Coffey M, Jin H (2011) Bacteria-responsive microRNAs regulate plant innate immunity by modulating plant hormone networks. Plant Mol Biol. 75: 93-105. 
Zhang LW, Song JB, Shu XX, Zhang Y, Yang ZM (2013) miR395 is involved in detoxification of cadmium in Brassica napus. J Hazard Mater. 12: 182.

Zhang Q, Zhao C, Li M, Sun W, Liu Y, Xia H, Sun M, Li A, Li C, Zhao S, Hou L, Picimbon JF, Wang X, Zhao Y (2013) Genome-wide identification of Thellungiella salsuginea microRNAs with putative roles in the salt stress response. BMC Plant Biol. 13: 180.

Zhao M, Ding H, Zhu JK, Zhang F, Li WX (2011) Involvement of miR169 in the nitrogen-starvation responses in Arabidopsis. New Phytol. 190: 906-915.

Zhao M, Tai H, Sun S, Zhang F, Xu Y, Li WX (2012) Cloning and characterization of maize miRNAs involved in responses to nitrogen deficiency. PLoS One. 7: e29669.

Zhao X, Li L (2013) Comparative analysis of microRNA promoters in Arabidopsis and rice. Genomics Proteomics Bioinformatics. 11: 56-60.

Zhao X, Liu X, Guo C, Gu J, Xiao K (2013) Identification and characterization of microRNAs from wheat (Triticum aestivum L.) under phosphorus deprivation. J Plant Biochem Biot. 22: 113-123.

Zhao YY, Guo L, Lu WJ, Li XJ, Chen HM, Guo CJ, Xiao K (2015) Expression pattern analysis of microRNAs in root tissue of wheat (Triticum aestivum L.) under normal nitrogen and low nitrogen conditions. J Plant Biochem Biot. 24: 143-153. Zhao YY, Lin S, Qiu ZB, Cao DC, Wen JL, Deng X, Wang XH, Lin JX, Li XJ (2015) MicroRNA857 is involved in the regulation of secondary growth of vascular tissues in Arabidopsis. Plant Physiol. 169: 2539-2552.
Zheng ZL (2009) Carbon and nitrogen nutrient balance signaling in plants. Plant Signal Behav. 4: 584-591.

Zhou J, Jiao F, Wu Z, Li Y, Wang X, He X, Zhong W, Wu P (2008) OsPHR2 is involved in phosphate-starvation signaling and excessive phosphate accumulation in shoots of plants. Plant Physiol. 146: 1673-1686.

Zhou H, Liu QJ, Li J, Jiang DG, Zhou LY, Wu P, Lu S, Li F, Zhu LY, Liu ZL, Chen LT, Liu YG, Zhuang CX (2012) Photoperiod- and thermo-sensitive genic male sterility in rice are caused by a point mutation in a novel noncoding RNA that produces a small RNA. Cell Res. 22: 649-660.

Zhou ZS, Song JB, Yang ZM (2012a) Genome-wide identification of Brassica napus microRNAs and their targets in response to cadmium. J Exp Bot. 63: 4597-4613.

Zhou ZS, Zeng HQ, Liu ZP, Yang ZM (2012b) Genome-wide identification of Medicago truncatula microRNAs and their targets reveals their differential regulation by heavy metal. Plant Cell Environ. 35: 86-99.

Zhou Y, Liu X, Engstrom EM, Nimchuk ZL, Pruneda-Paz JL, Tarr PT, Yan A, Kay SA, Meyerowitz EM (2015) Control of plant stem cell function by conserved interacting transcriptional regulators. Nature. 517: 377-380.

Zhu YY, Zeng HQ, Dong CX, Yin XM, Shen QR, Yang ZM (2010) MicroRNA expression profiles associated with phosphorus deficiency in white lupin (Lupinus albus L.). Plant Sci. 178: 23-29.

Zorb C, Senbayram M, Peiter E (2014) Potassium in agriculture-status and perspectives. J Plant Physiol. 171: 656-669. 